\title{
Investigation of Multistage Hydraulic Fracture Optimization Design Methods in Horizontal Shale Oil Wells in the Ordos Basin
}

\author{
Suotang Fu, ${ }^{1,2}$ Jian Yu, ${ }^{3}$ Kuangsheng Zhang, ${ }^{1,2}$ Hanbin Liu, ${ }^{1,2}$ Bing Ma $\mathbb{D}^{1,2}$ and Yuliang Su${ }^{4}$ \\ ${ }^{1}$ CNPC Changqing Oilfield, Xi'an Shaanxi, China 710018 \\ ${ }^{2}$ State Key Laboratory for Exploration and Development of Low Permeability Oil \& Gas Fields, Xi'an Shaanxi, China 710018 \\ ${ }^{3}$ CNPC Changqing Oilfield Exploration Institute, Xi'an Shaanxi, China 710018 \\ ${ }^{4}$ School of Petroleum Engineering, China University of Petroleum (East China), No. 66, Changjiang West Road, Huangdao District, \\ Qingdao, China 266580
}

Correspondence should be addressed to Bing Ma; 18823354@qq.com

Received 7 April 2020; Revised 19 June 2020; Accepted 27 June 2020; Published 21 September 2020

Academic Editor: Wei Wei

Copyright (C) 2020 Suotang Fu et al. This is an open access article distributed under the Creative Commons Attribution License, which permits unrestricted use, distribution, and reproduction in any medium, provided the original work is properly cited.

\begin{abstract}
Based on the analysis of the typical Ordos well groups, this study began with the accurate characterization of the fracture geometry by adopting advanced laboratory experiment methods and monitoring techniques. Then, with the integration of fracture geometry characterization and in situ stress distributions, fracture optimizations of the target wells were performed through numerical simulations methods. Finally, this study established a sweet spot prediction and identification method for long horizontal shale oil wells and constructed a set of optimization design methods for multistage hydraulic fracturing. This investigation revealed that the hydraulic fractures in Chang-7 terrestrial shale oil reservoirs exhibited the belt pattern, and the primary fractures generated the secondary fractures, which activated the natural fractures and induced shear failure. Macroscopic fractures were found to be perpendicular to the direction of the minimum principal stress. Secondary fractures and activated natural fractures were distributed around the primary fracture in the form of fracture types I and II. Multicluster perforation optimization techniques, which were based on shale reservoir classification and evaluation, and aimed at activating multiclusters and determining fracture sweet spots, were developed. These were successfully applied to the field operation and achieved production enhancement performance.
\end{abstract}

\section{Introduction}

Ordos Basin Chang-7 shale oil specifically refers to the oil in the 7th member of the Triassic Yanchang Formation, which is generated and accumulated within the tight sandstone and shale source rock without covering long migration distances [1]. Compared to other domestic shale oils in China, Chang-7 shale oil has low pressure and poor reservoir properties; however, it also has low viscosity and shallow buried depth. Compared to the Permian Basin shale oil, Chang-7 shale oil features low brittleness index, pressure gradient, and undeveloped natural fractures $[1,2]$. These characters lead to drilling and stimulation challenges in the economic and effective development of Chang-7 shale oil. Hydraulic fracturing is the primary method to increase oil recovery of shale reservoirs. The region filled with a complex fracture network during hydraulic fracturing stimulation is created, which is defined as the stimulated reservoir volume (SRV). Research proves that the SRV area is the main contribution of production in unconventional reservoirs [3]. The two main challenges are the difficulties in maximizing the SRV due to a low brittleness index and large horizontal stress differences, along with the rapid production decline due to low reservoir pressure. Therefore, it is essential to conduct an investigation on multiscale fracture characterization and fracture design optimization in order to promote efficient oilfield development.

Large-scale laboratory experiment simulations of hydraulic fracturing have played a vital role in understanding the mechanism of complex fracture propagation and simulating field operations [3]. As understanding the complexity of hydraulic fractures is challenging $[4,5]$, laboratory 
experiments can be performed to better control the experimental conditions, gradually understand the complexity of artificial fractures, evaluate the effectiveness of fracture monitoring methods, and provide a basis for guiding on-site hydraulic fracturing. Methods of direct observation and indirect study can be adopted to examine fracture propagations. Direct observation mainly refers to study of the post-frac core samples and fracture visualizations, such as PMMA for direct observation of fracture propagation process [6, 7]. Indirect study is the indirect analysis of fracture characteristics by detecting the signals generated during fracture propagation, mainly including acoustic emission (AE) and acoustic wave technology, CT scanning, DIC technology, fiber optic measurement technology, and electromagnetic signal monitoring [8]. Acoustic emission technology can detect the acoustic signals of rock fractures, while acoustic wave technology inverts the shape of fractures by actively transmitting acoustic signals and then receiving the reflected signals. Acoustic emission localization is a common method to study acoustic emission activities of rocks, and it is also the most developed method to monitor the fracture propagations $[9,10]$. Acoustic waves were first applied to detect the laboratory hydraulic fracture propagations by researchers from the University of Delft, who also detected the fracture tips, fluid edges, and fracture widths. However, this method has limitations in field applications [11, 12]. Synchrotron $\mathrm{X}$-ray microtomography is applied to observe the threedimensional (3D) real-time fracture propagations and investigate the effects of mircofractures, grain boundaries, and pore sizes on fracture toughness and propagation directions [13]. AlTammar and Sharma employed DIC technology to observe the displacement field changes around fractures and changes in pore pressure field changes caused by fracturing fluid filtration [14]. Because fiber optic materials have the characteristics of antielectromagnetic interference, antienvironmental noise, electrical insulation, and robust safety performance, they have been widely used in harsh environments for downhole measurement, and they have also begun to be applied in hydraulic fracturing monitoring $[15,16]$. During hydraulic fracture propagations, ions in the reservoir continue to dissolve into the fracturing fluid to form a current and generate a magnetic signal, which can reflect the propagation of the fractures. However, due to the high detection accuracy requirements of this technology, no field applications have been carried out [17].

Accurate identification of sweet spots in shale reservoirs is the basic prerequisite to improve the effect of shale reservoir stimulations. The classification and evaluation of engineering sweet spots in the Ordos Basin is important for guiding fracture stage selections for multistage fractures in shale oil reservoirs. The determination of sweet spots is closely related to rock brittleness, fracture toughness, natural fractures, and in situ stress, which can be measured using fracability and brittleness index. Chong et al. summarized the hydraulic fractures in the Barnett shale in Texas and defined fracability as the property that the reservoir can be effectively fractured to obtain increased production capacity [18]. Mullen and Enderlin posited that fracability is not only associated with geomechanical properties and proposed the complex fracability index model, which integrated rock properties, geomechanics, fracture toughness, and natural fractures into a single index [19]. The higher the complex fracability index value, the easier it is to generate a complex fracture network. Fang and Amro compared the fracability of the terrestrial and marine shale, determining that the fracability of the former is more complicated [20]. The effects of the brittleness index, mineral content, natural fracture, diagenesis, and sedimentation on fracability were studied, and it was concluded that the fracability calculation methods should be further improved. $\mathrm{Hu}$ et al. [21] examined the effect of confining pressure on shale compressive strength, Young's modulus, Poisson's ratio, and number of microcracks, introducing fracture toughness and establishing a new brittleness calculation model [21]. Jin et al. [22] integrated the critical energy release rate with the brittleness and proposed a fracability index model, which provided a reference for distinguishing the fracture target zone and optimized horizontal well trajectory and perforation cluster spacing [22]. Xu and Sonnenberg [23] described the geomechanical properties of the Bakken shale based on well logging data, triaxial tests, rebound impact tests, and X-ray data, and proposed a new mineralogy-based brittleness index and proved the significant positive correlation between mineralogy and the brittleness index model [23].

Combining shale oil reservoir engineering-based sweet spot identification with geological sweet spot descriptions to determine optimal fracturing programs is the current trend of shale oil development [24]. Liu et al. [25] optimized the multistage fracture spacing and perforation locations based on the analysis of reservoir and engineering combined sweet spots [25]. Wigger et al. [26] applied the similar method and optimized the development plan for Eagle Ford shale reservoir [26]. Brittleness index and fracability have been extensively studied; however, the studied brittleness index and fracability models are limited in applicability to specific reservoirs.

In addition to laboratory experiments, fiber optic materials were first used in this study to reflect fracture propagation. Based on the specific fracture network, the fracture optimizations of the target wells are performed through numerical simulations methods. Finally, a suitable method to determine the sweet spots and design the fracture program is proposed to develop the shale oil reservoirs in the Ordos Basin.

\section{Laboratory Experimental Investigation}

2.1. Experiment Equipment and Setup. This experimental study used the High Temperature High Pressure (HTHP) Fracture Simulation System, and $50 \mathrm{MPa}$ triaxial stresses are applied to the $30 \times 30 \times 30 \mathrm{~cm}^{3}$ specimen under $100^{\circ} \mathrm{C}$ (Figure 1).

The specimen is composed of 40-70 mesh quartz sand mixed with composite Portland Cement in a $1: 1$ ratio. The mechanical properties of the specimen are shown in Table 1.

Twelve AE sensors are placed on the four sides of the specimen (Figure 2(a)) and fixed in the AE hole during the 


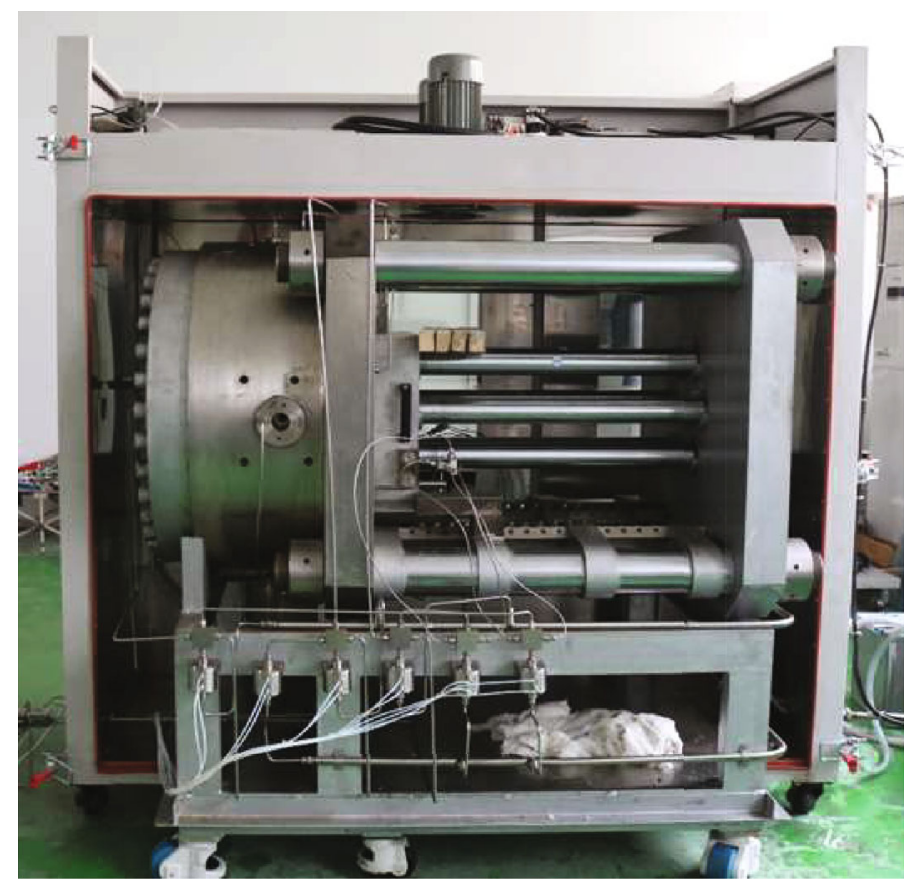

(a)

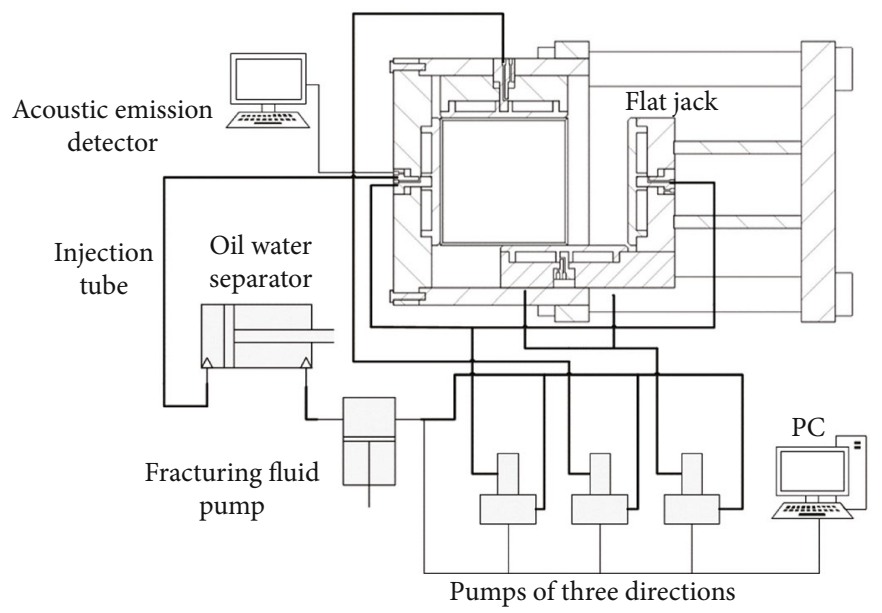

(b)

FIgURE 1: Schematics of (a) the HTHP fracture system and (b) the experiment setup.

TABLE 1: Mechanical properties of the artificial cement specimen.

\begin{tabular}{lc}
\hline Parameters & Value \\
\hline Fracture toughness $(\mathrm{MPa} \sqrt{\mathbf{m}})$ & 0.7 \\
Uniaxial compressive strength $(\mathrm{MPa})$ & $\mathbf{2 7 . 9 8} \pm \mathbf{1}$ \\
Tensile strength $(\mathrm{MPa})$ & $\mathbf{3 . 5 5} \pm \mathbf{0 . 2}$ \\
Poisson's ratio & 0.17 \\
Elastic modulus $(\mathrm{GPa})$ & 24.6 \\
\hline
\end{tabular}

experiment (Figure 2(b)). The threshold of the AE analysis system is set to $40 \mathrm{~dB}$ and the sampling frequency is $10 \mathrm{MHz}$. The experiment simulated the open-hole multistage fracture beginning from the toe, and the hole length is $15 \mathrm{~cm}$.
2.2. Experiment Program. In order to study the acoustic emission distribution during fracture propagation, two stress differences of $5 \mathrm{MPa}$ and $10 \mathrm{MPa}$ were set. The experiment fluid is $2 \%$ guar fluid with a viscosity of $106 \mathrm{cp}$. The parameters used in the experiment are listed in Table 2.

\subsection{Fracture Network Characterization and Controlling} Factors. The specimens are cut off after the experiment to observe the fracture geometry. As shown in Figure 3, the red surface represents the fracture surface. Due to the stress concentration at the bottom of the hole, the fracture propagates along the inclined surface in an elliptical shape (Figure 3(a)). As the stress difference increases, the fracture surface becomes a plane fracture nearly perpendicular to the minimum in situ stress (Figure 3(b)). 


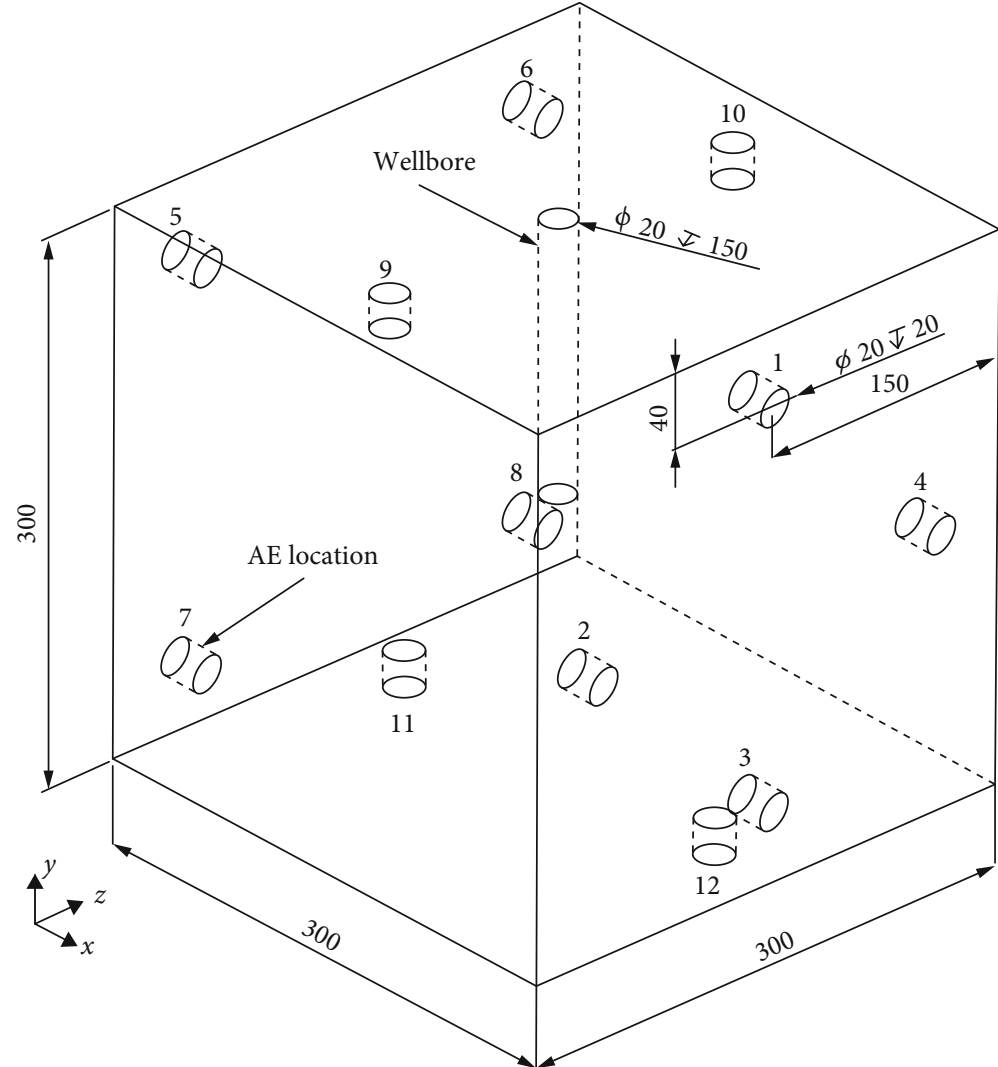

(a)

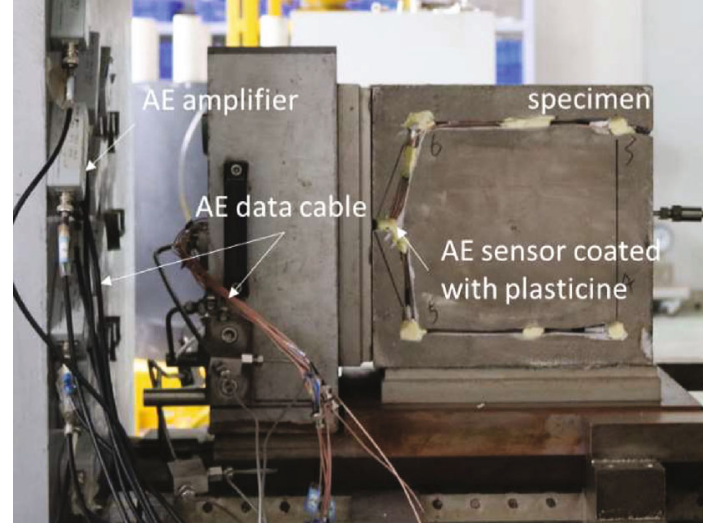

(b)

FIGURE 2: Schematic of the AE hydraulic fracturing system.

TABLE 2: Experimental parameters for water-based fracturing.

\begin{tabular}{lccc}
\hline $\begin{array}{l}\text { No. of } \\
\text { specimens }\end{array}$ & Fluid & $\begin{array}{c}\sigma_{v}-\sigma_{H}-\sigma_{h} \\
(\mathrm{MPa})\end{array}$ & $\begin{array}{c}\text { Rate } \\
(\mathrm{mL} / \mathrm{min})\end{array}$ \\
\hline $1 \#$ & Water + & $32-26-21$ & 2 \\
$2 \#$ & guar & $32-26-16$ & \\
\hline
\end{tabular}

The energy of the acoustic emission signal is divided into three categories. Red represents the highest energy level of the acoustic emission event, followed by blue, while the green energy level is the smallest. The highest energy level represents the main fracture trajectory, as shown in Figure 4. A large number of high-level and low-level acoustic emission events are gathered around the primary fracture, indicating the existence of secondary fractures around the primary fracture. The width of the fracture generated in the lab experiment is $8-10 \mathrm{~cm}$.

As the stress difference increases, the number of acoustic emission events decrease, and the acoustic emission events are more dispersed, as shown in Figure 5. The increased stress difference results in a single form of the fracture; hence, acoustic emission is mainly distributed on the primary fracture surface. Moreover, the fracture network is not formed, i.e., the fracture zone is not obvious.
In order to analyze the microfracture morphology, the fracture surface of specimen \#1 was selected to undergo scanning electron microscopy (Figure 6). When hydraulic fractures extend to the grain particle boundary, fractures tend to extend along the particle boundary, which lead to fracture reorientation or generation of fracture branches. This phenomenon is difficult to observe on the macrofracture surface. The generation of microfractures is in line with the band-shaped distribution of acoustic emission events, i.e., there are a large number of acoustic emission signals around the primary fractures.

The band-distributed acoustic emission events and microfracture distribution indicated the hydraulic fractures as fracture zones with a certain width. According to the in situ stress state and reservoir mechanical properties of Chang-7 shale reservoir, the experiment results indicated that the hydraulic fractures in Chang-7 reservoir would follow a fractured band pattern, which is different from that of the currently used multistage fracture models in the Ordos Basin. In the band-shaped fractures, the primary fracture generated the secondary fractures, which further activated the natural fractures and induced shear failure. Macrofractures are perpendicular to the direction of the minimum principal stress. Secondary fractures and activated natural fractures are distributed around the primary fracture in the form of type I and II failures. 


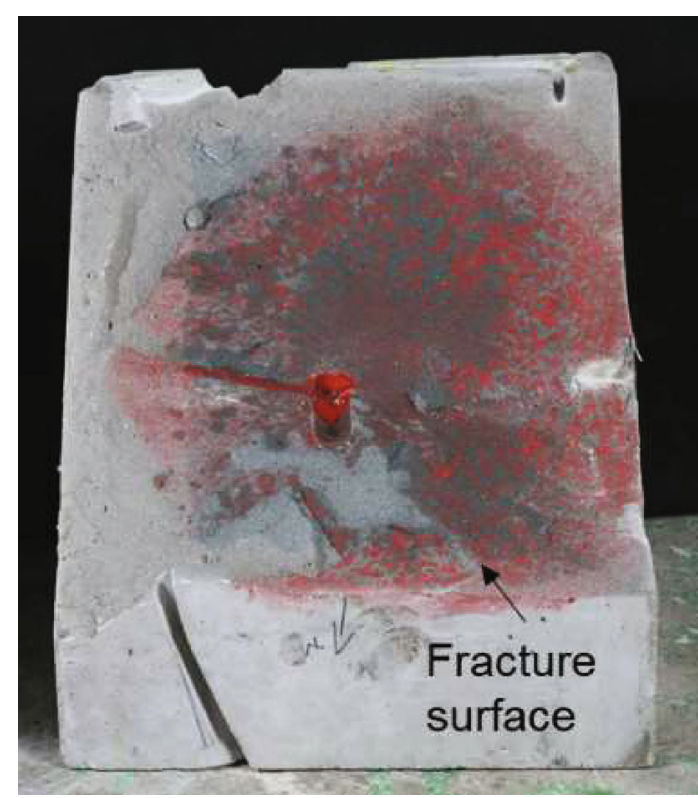

(a) Specimen \#1

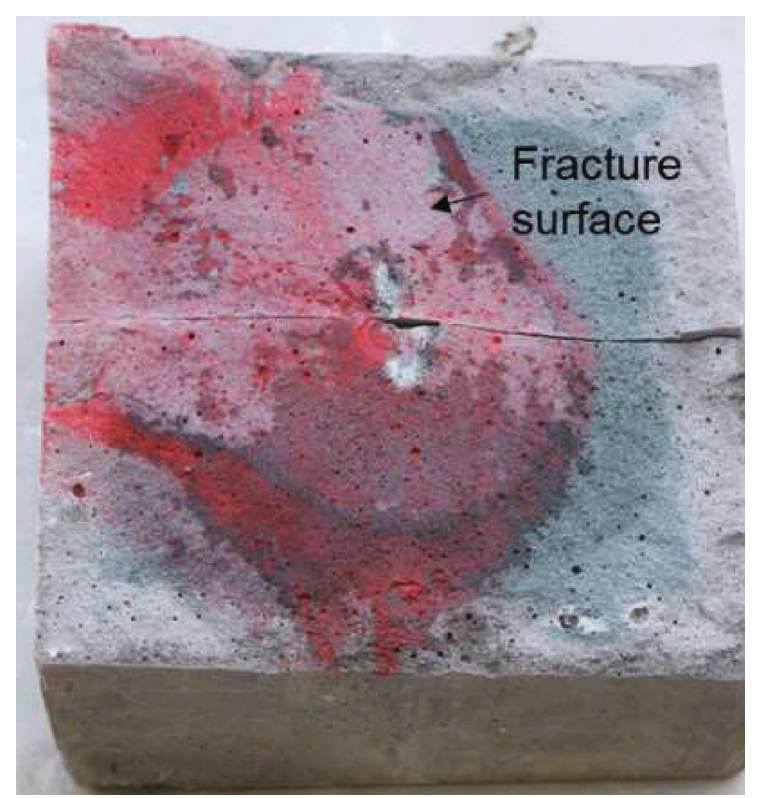

(b) Specimen \#2

Figure 3: Hydraulic fracture shape of the specimens.

\section{Investigation of 3D In Situ Stress and Fracture Parameter Optimizations}

3.1. 3D Reservoir Geomechanics. The magnitude and orientation of in situ stress have an important influence on the design, implementation, and evaluation of hydraulic fracturing. The 3D geomechanical modeling begins with the geological model, integrates multiwell 1D geomechanical models and adopts the 3D geomechanical workflow established specifically for shale reservoirs. The finite element analysis (VISAGE) was used to establish a three-dimensional geomechanical model to more accurately determine the threedimensional spatial distribution of the geostress field. It combined seismic, geological, well logging, core, imaging, and 1D geomechanical models, comprehensively characterized by the reservoir heterogeneity, anisotropic stress field, and other key $3 \mathrm{D}$ engineering parameters. This study selected a rectangular area of $2680 \mathrm{~m} \times 5460 \mathrm{~m}$ from X platform as the research target.

3.1.1. 3D FEM Gridblocks. To avoid the interference of the boundary effect on the simulation results of the reservoir stress field, the geomechanical grid needs to be extended in the horizontal direction, generally 2 to 3 times the plane size of the geological model; in order to ensure the stability of the FEM simulation, the extended gridblock of the underlaying formation is basically consistent with the overlying formation. In addition to the extended grids, this study also added the overlying rock layer, the underlying rock layer, and the lateral rock layer, covering the range from the ground to a depth of approximately $4200 \mathrm{~m}$. The total number of elements is 10.53 million, the horizontal accuracy of the target layer grid is $20 \mathrm{~m}$, and the vertical accuracy is approximately
$0.5 \mathrm{~m}$. The grid sizes of the overburden, underburden, and lateral rock layers outside the reservoir site gradually transition to the coarse grid.

3.1.2. 3D Geomechanical Parameters. The well logging data and 1D geomechanical data of 3 vertical wells and 12 horizontal wells were used to perform $3 \mathrm{D}$ attribute interpolation. First, the $3 \mathrm{D}$ model is interpolated to obtain the $P$-wave time difference, $S$-wave time difference, and density attribute volume. On this basis, dynamic elastic parameters are calculated, including dynamic Young's modulus and dynamic Poisson's ratio, and static and dynamic transformations are performed to obtain static elastic parameters. Rock strength parameters were calculated according to the formula obtained in the $1 \mathrm{D}$ geomechanical study, including uniaxial compressive strength (UCS), tensile strength (TSTR), and internal friction angle (FANG), as shown in Figure 7.

Figure 8 showed the comparison of $1 \mathrm{D}$ (red) and 3D geomechanical parameters (colored), from left to right, as Young's modulus and Poisson's ratio. It can be seen that the $1 \mathrm{D}$ and $3 \mathrm{D}$ geomechanical parameters have good consistency, thus verifying the reliability of the mechanical parameters in the $3 \mathrm{D}$ model.

3.1.3. Boundary Conditions. The value of horizontal in situ stress is mainly affected by overlying stress, pore pressure, and tectonic events. The effect of overburden stress is reflected in the model by the density and gravity of the overburden. The effect of pore pressure will be reflected by the input 3D pore pressure attribute volume in the FEM simulation. In the VISAGE simulation, the effect of tectonic events is reflected as the boundary conditions using the structural strain method (tectonic stress coefficient), which is used 

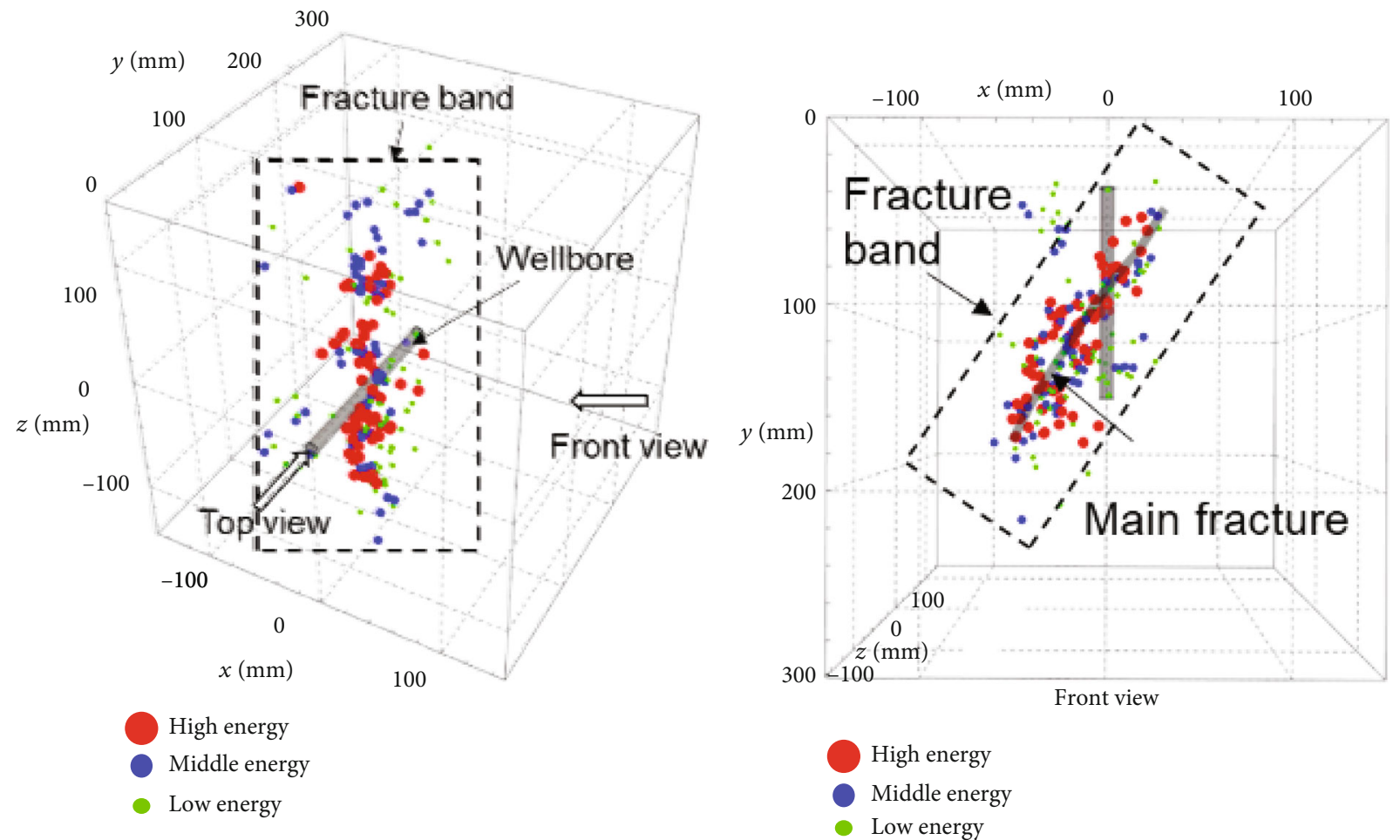

(a)

(b)

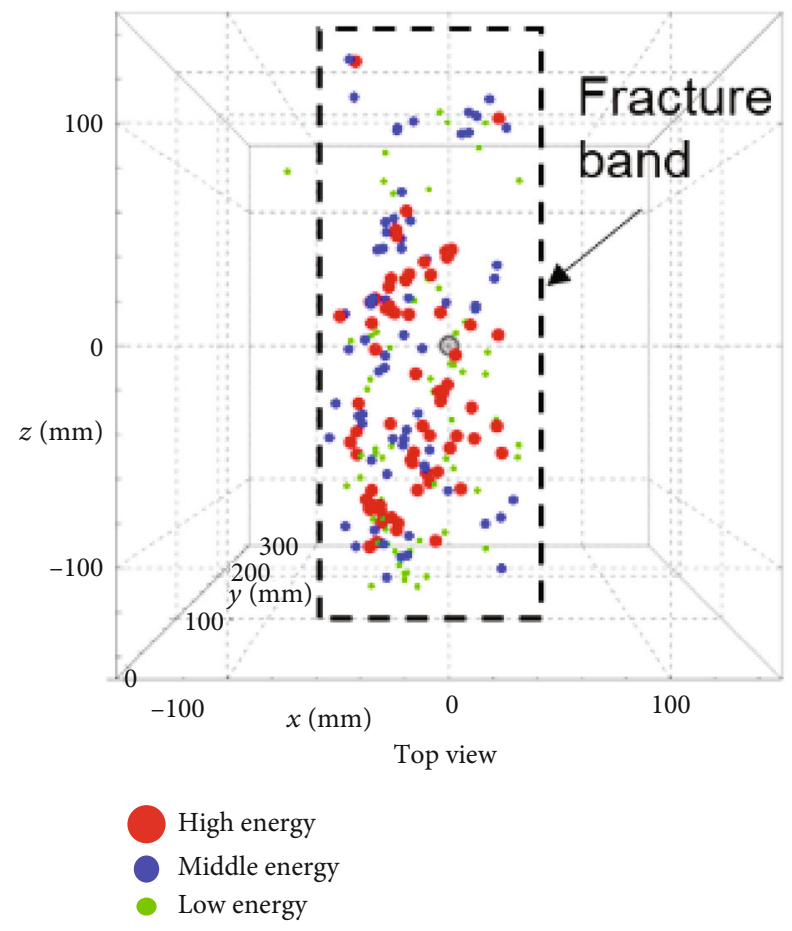

(c)

FIgURE 4: Different views of AE localization of specimen \#1.

to apply rock deformation caused by tectonic action on the boundary around the model. Similar to the $1 \mathrm{D}$ geomechanical model, the 3D model is based on long-term geomechanical research experience in Longdong area and uses 0.00012 and 0.00242 as the tectonic strain values in the direction of the minimum and maximum horizontal principal stress, respectively.

3.1.4. Simulation Results of In Situ Stress. Figure 9 showed the comparison of the 1D (black line) and 3D (colored) in 


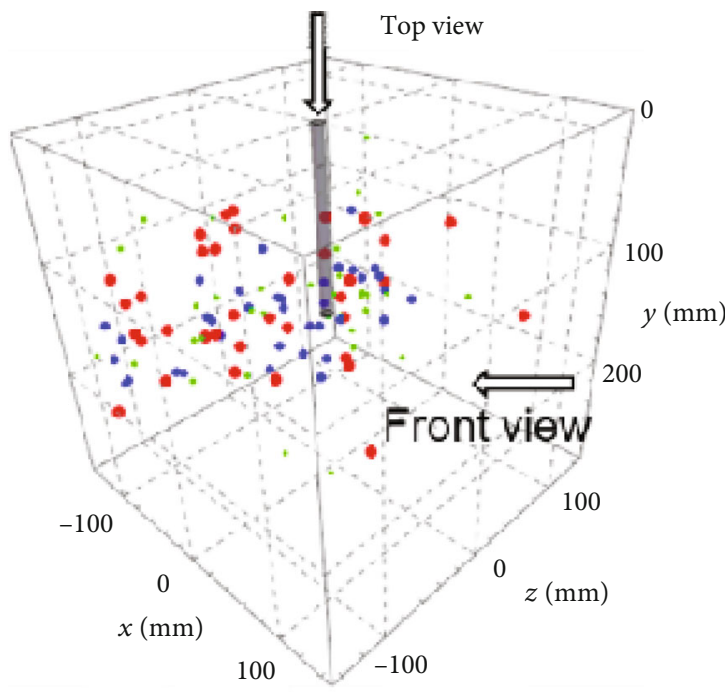

High energy

Middle energy Low energy

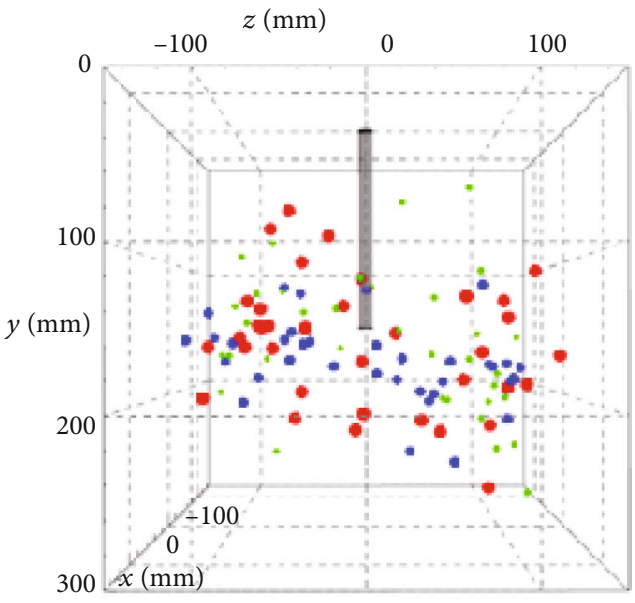

Front view

High energy

Middle energy

Low energy

(b)

(a)

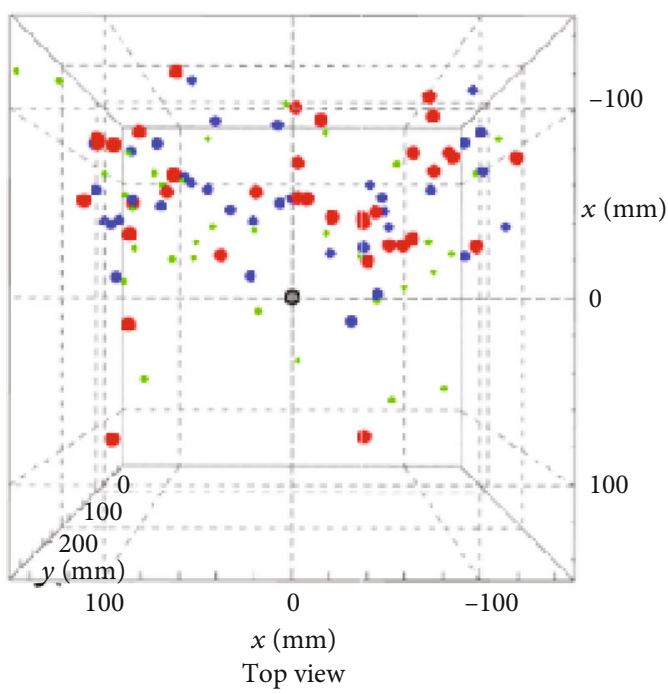

High energy

Middle energy

Low energy

(c)

FIGURE 5: Different views of the AE localization of specimen \#2.

situ stress results for some horizontal wells. From left to right, the overlying stress and the minimum and maximum horizontal principal stress are listed in order. It can be seen that the $1 \mathrm{D}$ and $3 \mathrm{D}$ in situ stress models show good consistency.

The 3D distribution of the $\mathrm{X}$ platform is shown in Figure 10. The 3D in situ stress distribution has a significant correlation with lithology. The stress of the mudstone layer is high, and it is simple to control fracture propagation. The minimum horizontal principal stress of sandstone is approximately $32 \mathrm{MPa}$ and that of mudstone is approximately $40 \mathrm{MPa}$.

3.2. Hydraulic Fracture Parameter Optimizations. Due to the unique sedimentary characteristics of shale oil reservoirs in the Ordos Basin, the sand bodies exhibit strong 


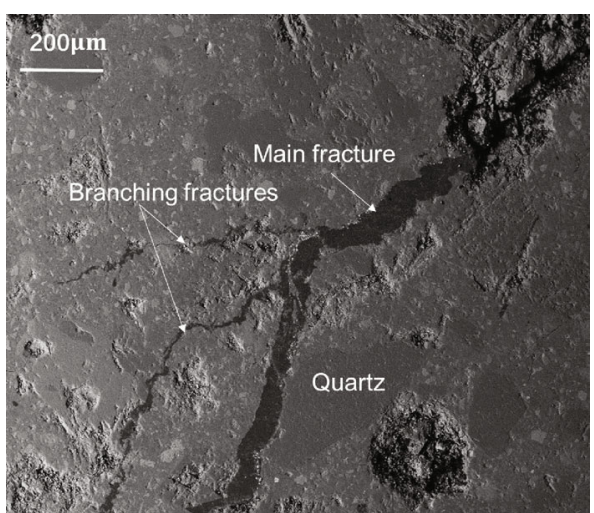

FIgURE 6: Microfracture morphology under a scanning electron microscope.

heterogeneity and well-developed natural fractures. Twelve horizontal wells are drilled on the X platform in the targeted zones of Chang- $7_{1}^{2}$ and Chang- $7_{2}{ }^{1}$ with a well spacing of 200-400 $\mathrm{m}$. Optimizations are conducted by considering the following factors: post-frac production control, influences of natural fractures, stress shadow and cluster spacing, stage length, well length, mudstone fracability, vertical stress shielding fluid system, and fluid/proppant volumes. Based on the previous research on the distribution of in situ stress, the "stress shadow" effect is introduced into the research of multicluster fracture initiation and expansion. This effect more accurately characterizes the competition between close-range hydraulic fracturing fractures.

\subsubsection{Fracture Propagations under Different Cluster Spacing.}

A $50 \mathrm{~m}$ horizontal section with good petrophysical properties are selected for well Y. The fracture propagations of cluster spacings of $2.5 \mathrm{~m}, 5 \mathrm{~m}, 10 \mathrm{~m}, 15 \mathrm{~m}$, and $20 \mathrm{~m}$ are examined under fixed fluid and proppant volume. The perforation location and study results are shown in Figure 11.

Figure 11 shows that the smaller the cluster spacing, the more obvious the stress interference between the fractures, and the length of the fractures in some perforated clusters is very limited, while some cannot even initiate cracks. However, after the cluster spacing is increased, the stress interference between perforated clusters becomes significantly smaller, fracture extension is guaranteed, and the length is increased. The simulated hydraulic fracture geometric parameters are shown in Table 3.

3.2.2. Productions under Different Cluster Spacing. The production forecast is conducted using the Petrel-IX simulator based on the fracture simulation results (Figure 12). It can be seen that as the fracture length increases, the pressure drawdown area increases. The pressure drawdown area further grows under increased number of fractures.

Under a fixed $400 \mathrm{~m}$ well spacing, the 1-year, 3-year, and 5-year cumulative production of different cluster spacings are plotted in Figure 13, which revealed that a $5 \mathrm{~m}$ cluster spacing resulted in the highest cumulative produc- tion, and hence, it is the optimum cluster spacing under given conditions.

Under a fixed $200 \mathrm{~m}$ well spacing, the 1-year, 3-year, and 5-year cumulative production of different cluster spacings are plotted in Figure 14, which revealed that the $5 \mathrm{~m}$ cluster spacing result in the highest cumulative production, and hence, it is the optimum cluster spacing under given conditions.

3.2.3. Stage Length and Number of Clusters. According to previous global unconventional oil and gas development experience, as the number of single-stage perforating clusters increases, the percentage of perforations that do not contribute to production increases. The perforation cluster of 4,5 , and 6 will result in the average effective production contribution clusters of $2.8,3.8$, and 3.1, respectively. In general, when the perforation clusters are more than 5, the effective perforation clusters are between 3 and 4 clusters on average, and the number of effective perforation clusters does not increase with the increase of the total perforation clusters (Figure 15). Therefore, the number of single-stage perforation clusters in Chang-7 shale reservoir stimulation is suggested to be no more than 5 .

\section{Optimization Design Methods of Multistage Fractures considering Engineering Sweet Spots}

4.1. Controlling Factors and Identification of Engineering Sweet Spots. The purpose of the engineering sweet spot evaluation is to select the optimum horizon section for hydraulic fracturing to achieve the optimal reservoir treatment. The identification of the geology and engineering integrated sweet spots in the Ordos Basin is conducted by fully utilizing the well logging data for the basic parameters [16]; the flowchart is as follows:

(1) Basic well logging data interpretation, including mud content, porosity, permeability, oil saturation, in situ stress, and rock mechanical properties

(2) Identification of geological sweet spots by interpreting mud content, porosity, permeability, and oil saturation

(3) Identification of engineering sweet spots by analyzing the minimum principle stress, brittleness index, and other mechanical parameters

(4) Statistical study of the parameters of geological and engineering sweet spots and establish classification criteria

(5) Comprehensively evaluate the geological and engineering sweet sport to determine the integrated sweet spots for hydraulic fracturing

The integrated sweet spot identification is performed based on the interpretation of logging and production data of 213 oil wells, as shown in Table 4, wherein type I, II, and III sweet spots are marked in red, yellow, and white, 


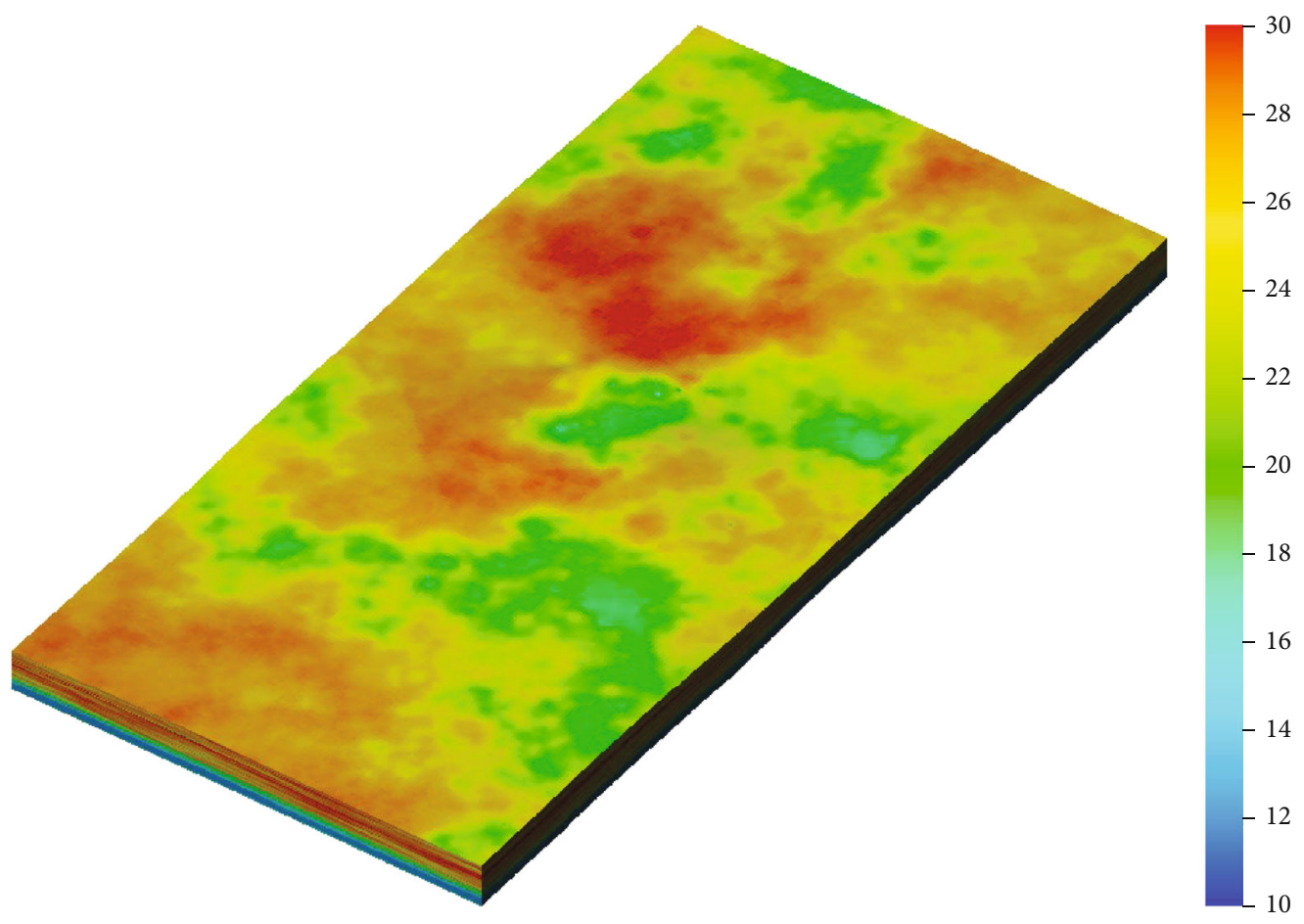

(a) Young's modulus
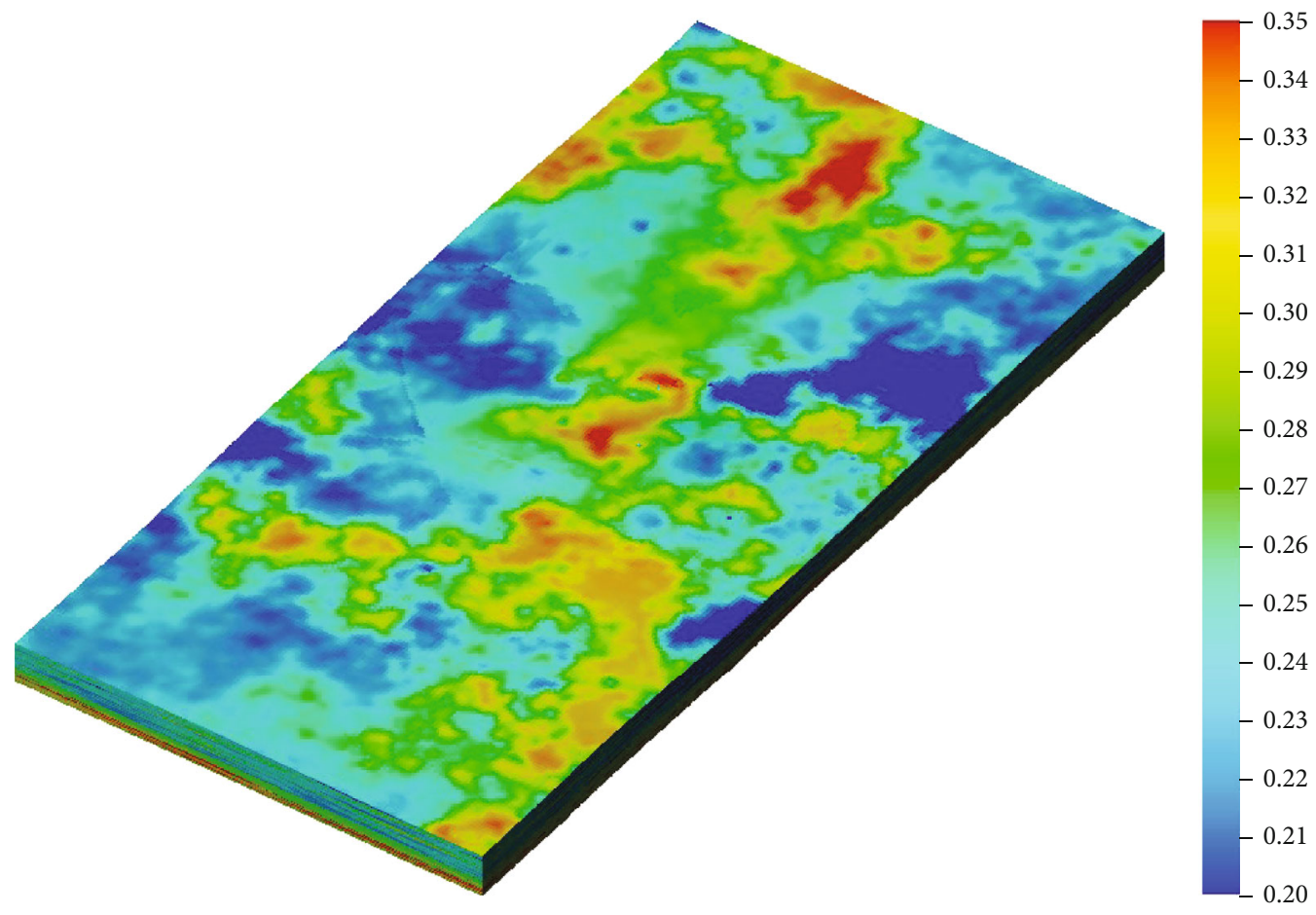

(b) Poisson's ratio

Figure 7: Continued. 


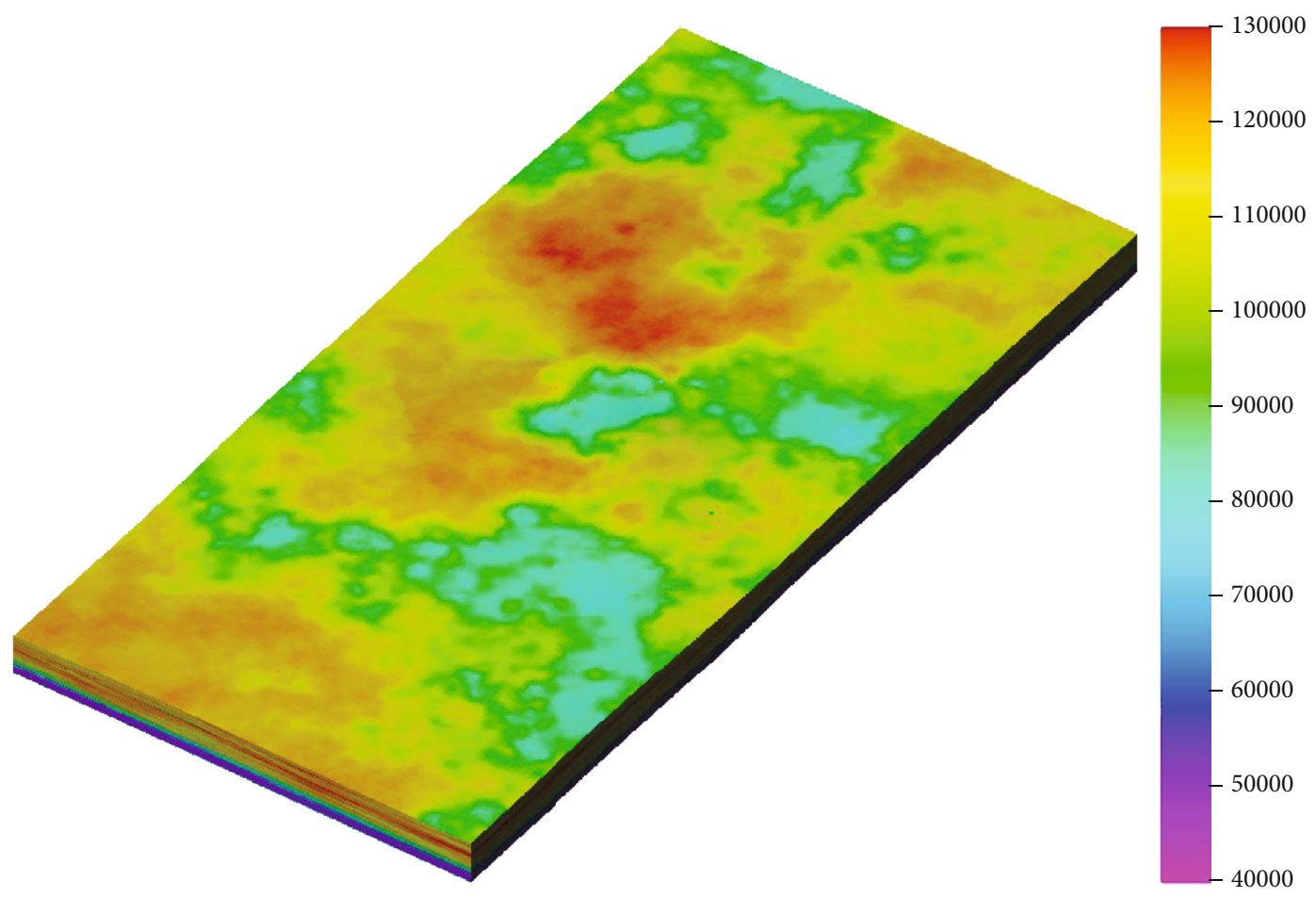

(c) Uniaxial compressive strength

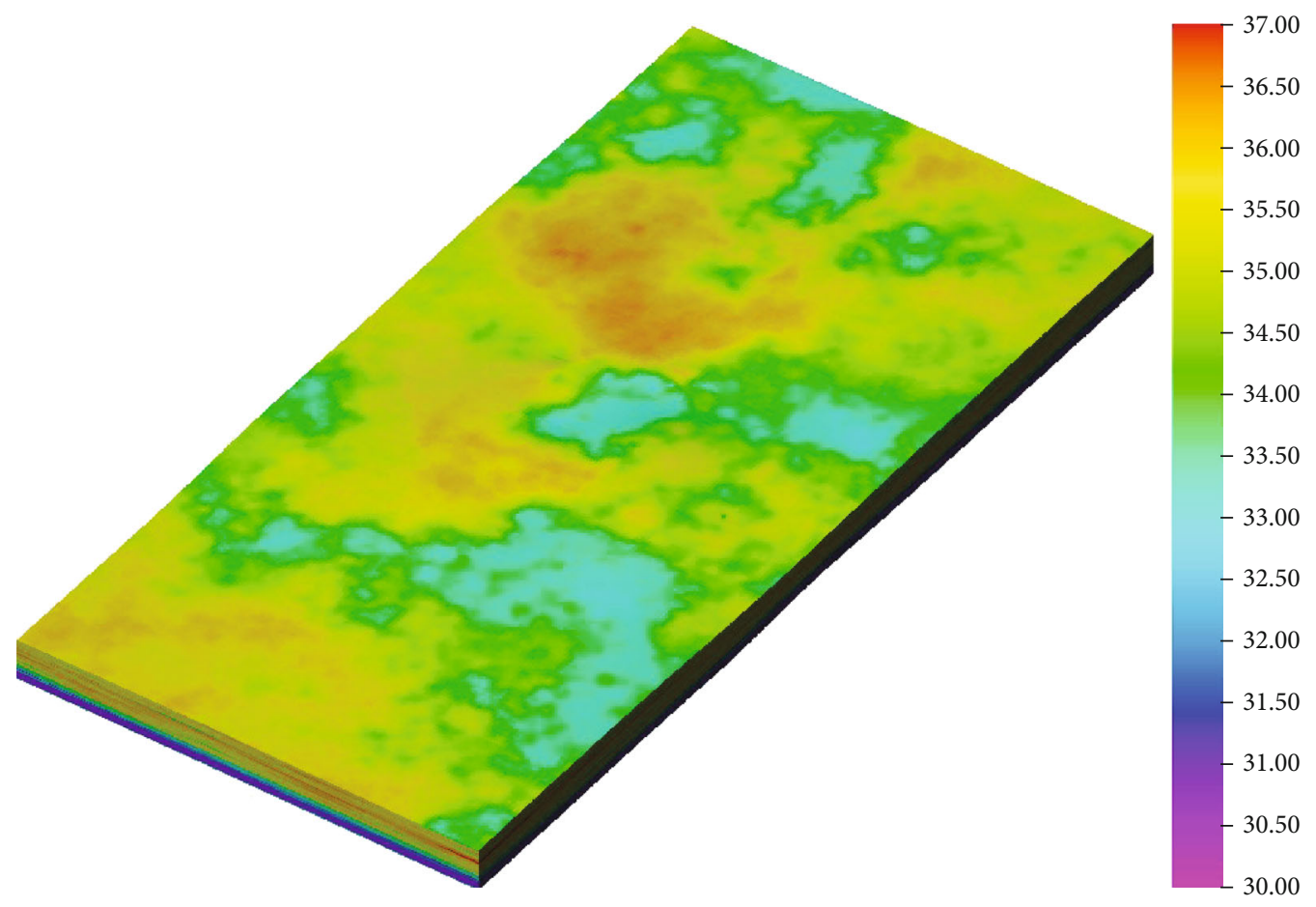

(d) Internal friction angle

FIgURE 7: 3D mechanical properties in this study.

respectively. The symbols $\Phi$ e, So, $\sigma_{\mathrm{h}}, \mathrm{BI}$, and Sh represent effective porosity, oil saturation, minimum horizontal stress, brittleness index, and mud content, respectively. The identification method is applied to well $\mathrm{Y}$, and the identification results are shown in Figure 16.
4.2. Optimization of Perforation in Multistage Hydraulic Fracturing. Perforation optimization is one of the major factors in multistage hydraulic fracturing, and the key is to achieve the optimum match for perforation and reservoir fracability. The perforation optimization requires a 

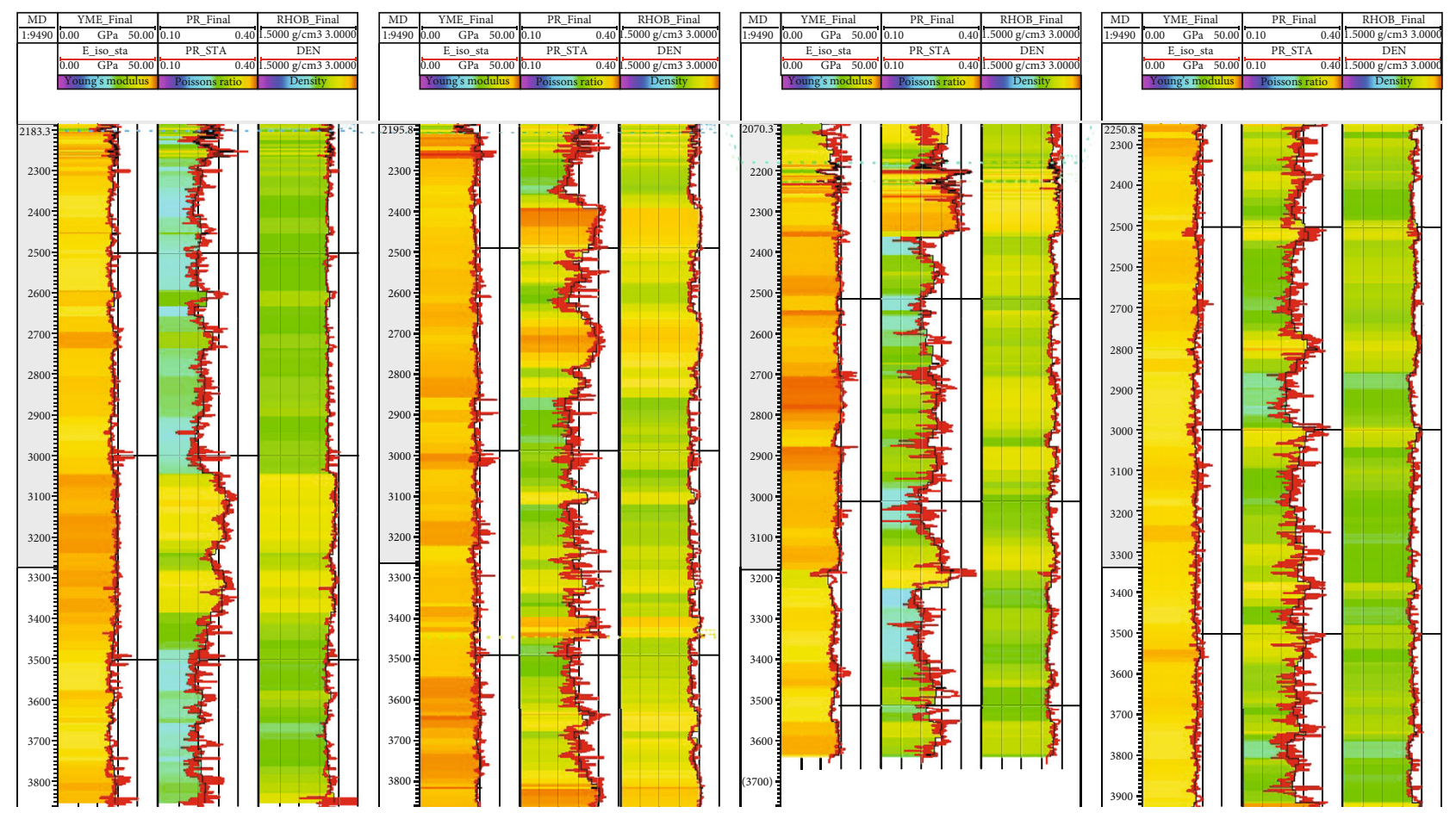

Figure 8: Comparisons of 1D (red line) and 3D (colored) mechanical properties in this study.
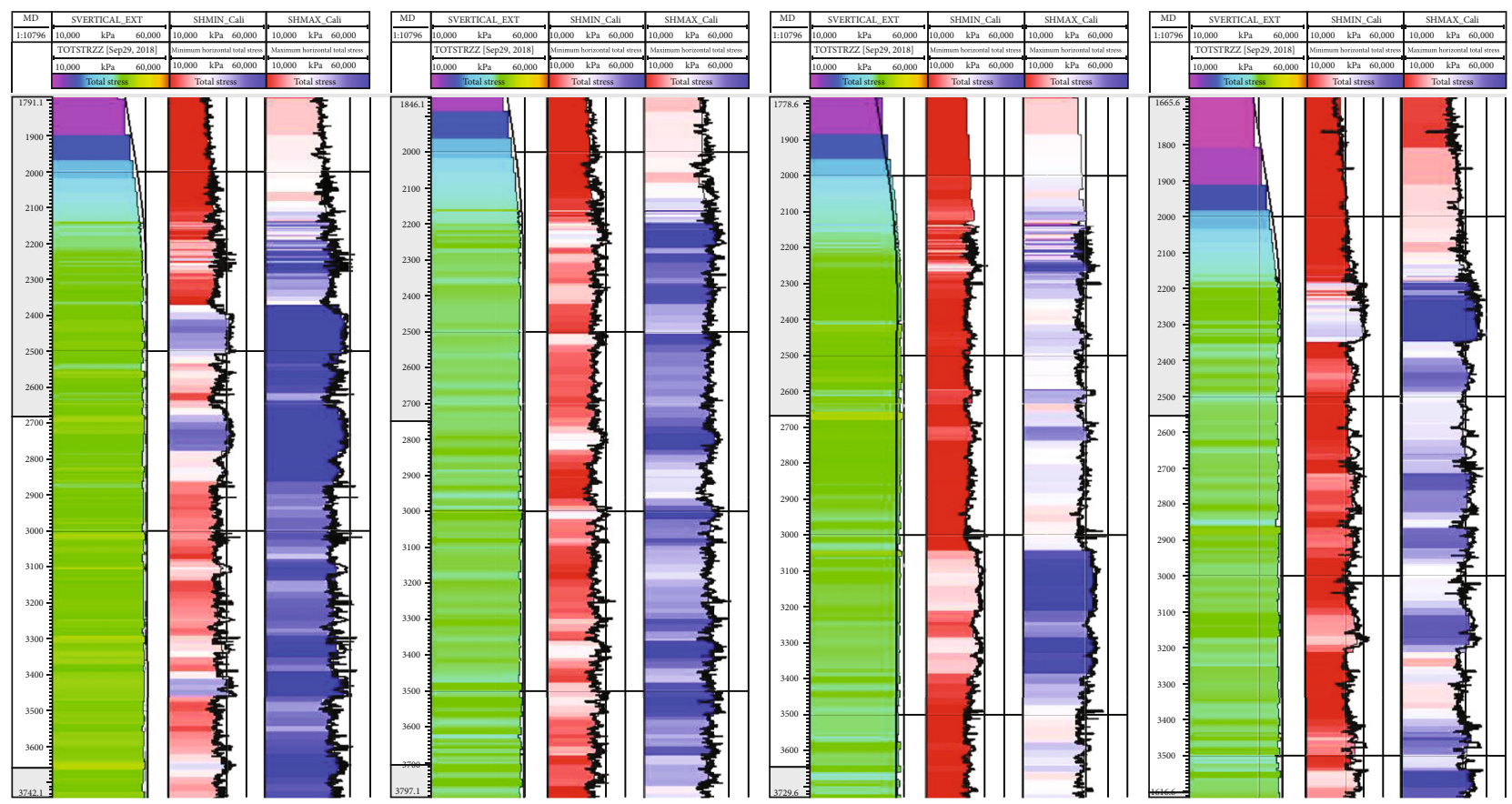

FIGURE 9: Comparison of the 1D (black line) and 3D (colored) in-situ stress results for some horizontal wells.

reasonable design for cluster spacing, cluster location, and number of holes, in order to ensure optimum reservoir stimulation. The operators proposed a perforation design specifically customized to the reservoir properties of Chang-7 reservoir.
(1) Based on the integrated geological and engineering sweet spot, the cluster spacing is differentiated. The 5-7 $\mathrm{m}$ cluster spacing is designed for the type I sweet spots, while the $8-12 \mathrm{~m}$ cluster spacing is designed for the type II sweet spots 


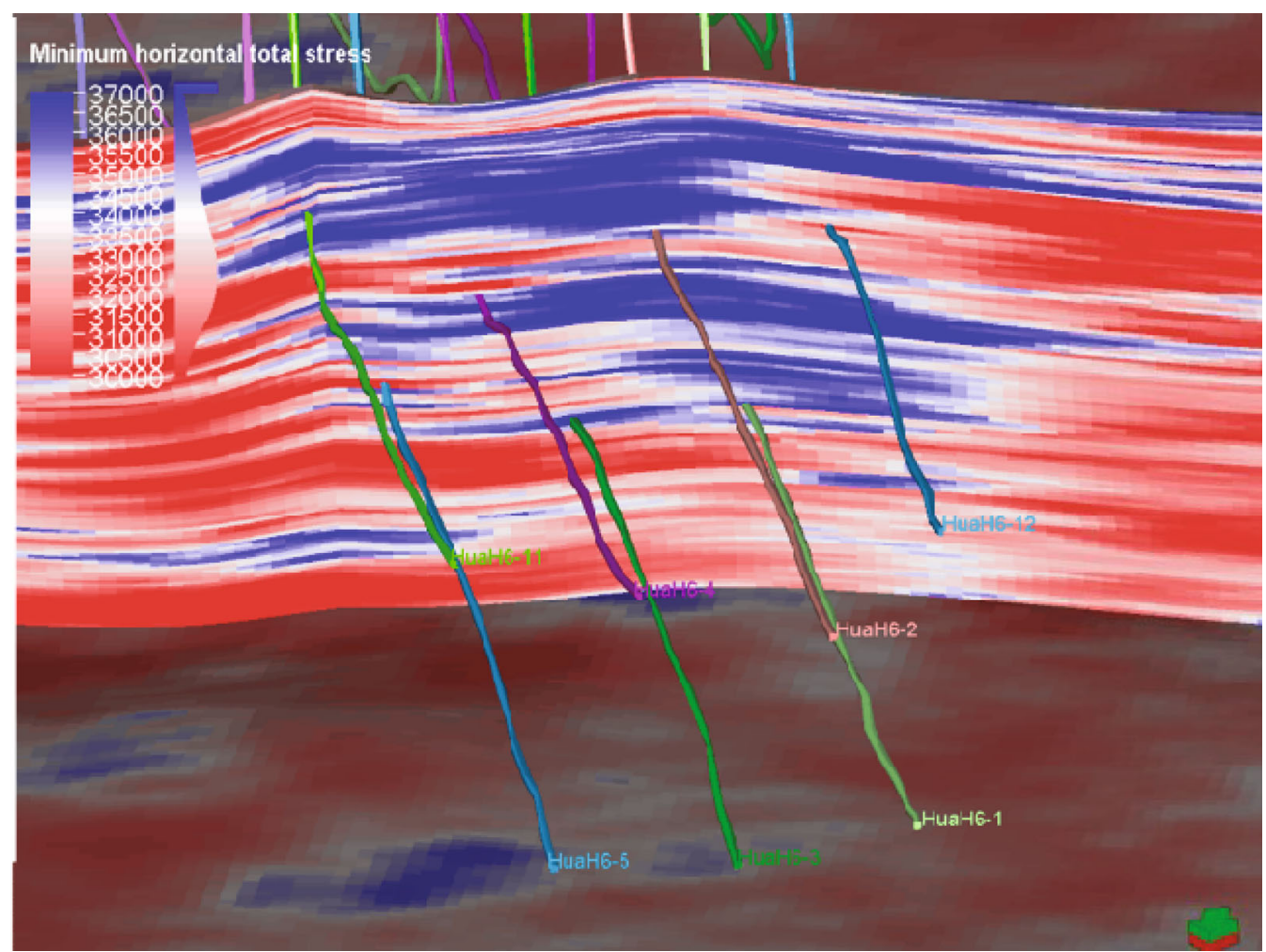

FIgURe 10: 3D distribution of the X platform.
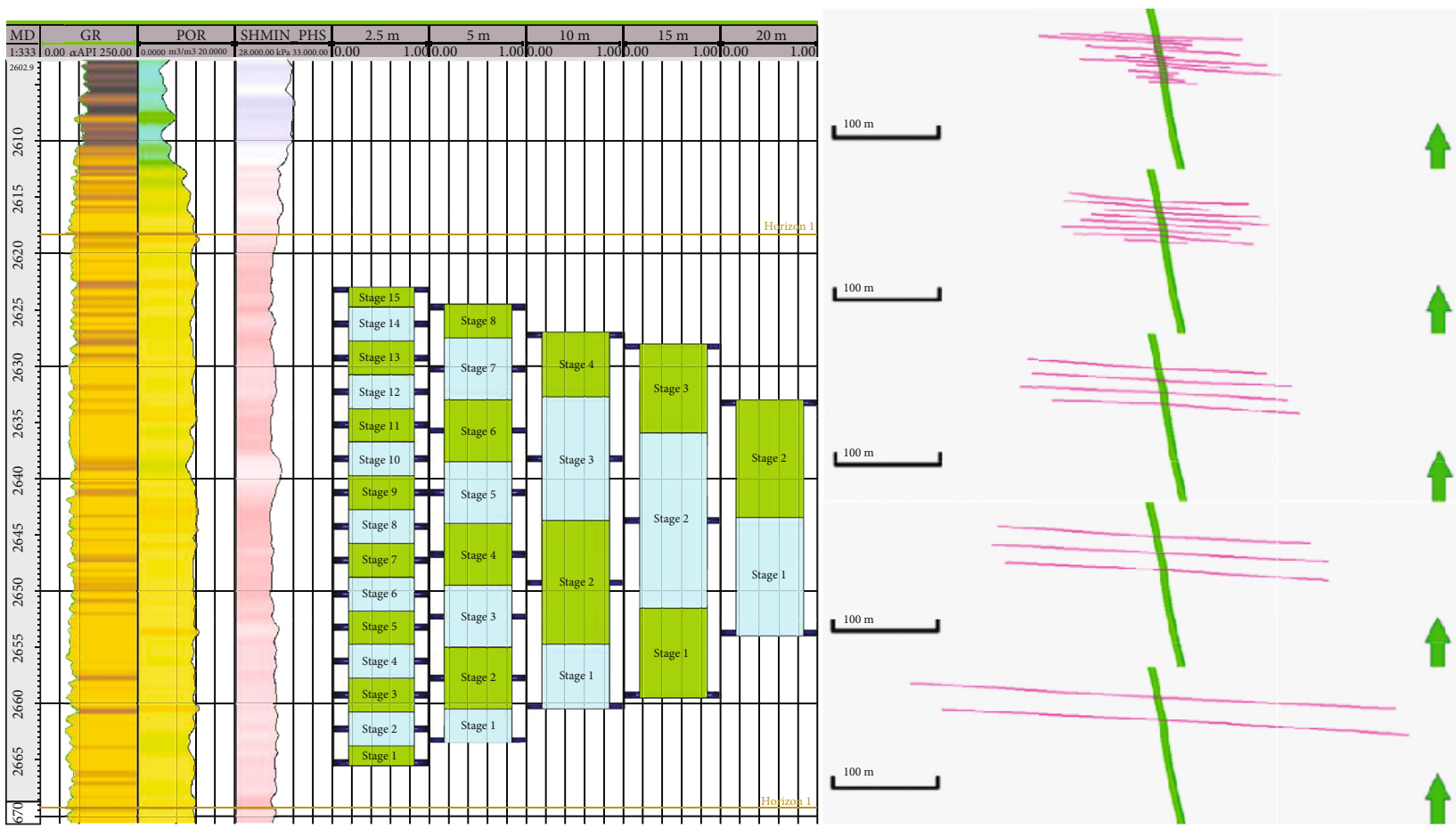

FIGURE 11: Locations of perforations and the fracture geometries.

(2) Considering the influence of mechanical properties and in situ stress differences on the simultaneous initiation of multicluster perforation, limited entry perforation technology is used to achieve effective initiation of multicluster fractures. Number 36-45 holes are placed in one cluster of perforation 
TABle 3: Parameters of the hydraulic fracture geometries under different cluster spacings.

\begin{tabular}{|c|c|c|c|c|c|}
\hline Cluster spacing $(\mathrm{m})$ & 2.5 & 5 & 10 & 15 & 20 \\
\hline Cluster number & 15 & 8 & 4 & 3 & 2 \\
\hline Average half length (m) & 33.8 & 67.1 & 113.6 & 146.0 & 217.5 \\
\hline Average fracture conductivity (md.m) & 837 & 818 & 945 & 1041 & 1013 \\
\hline
\end{tabular}

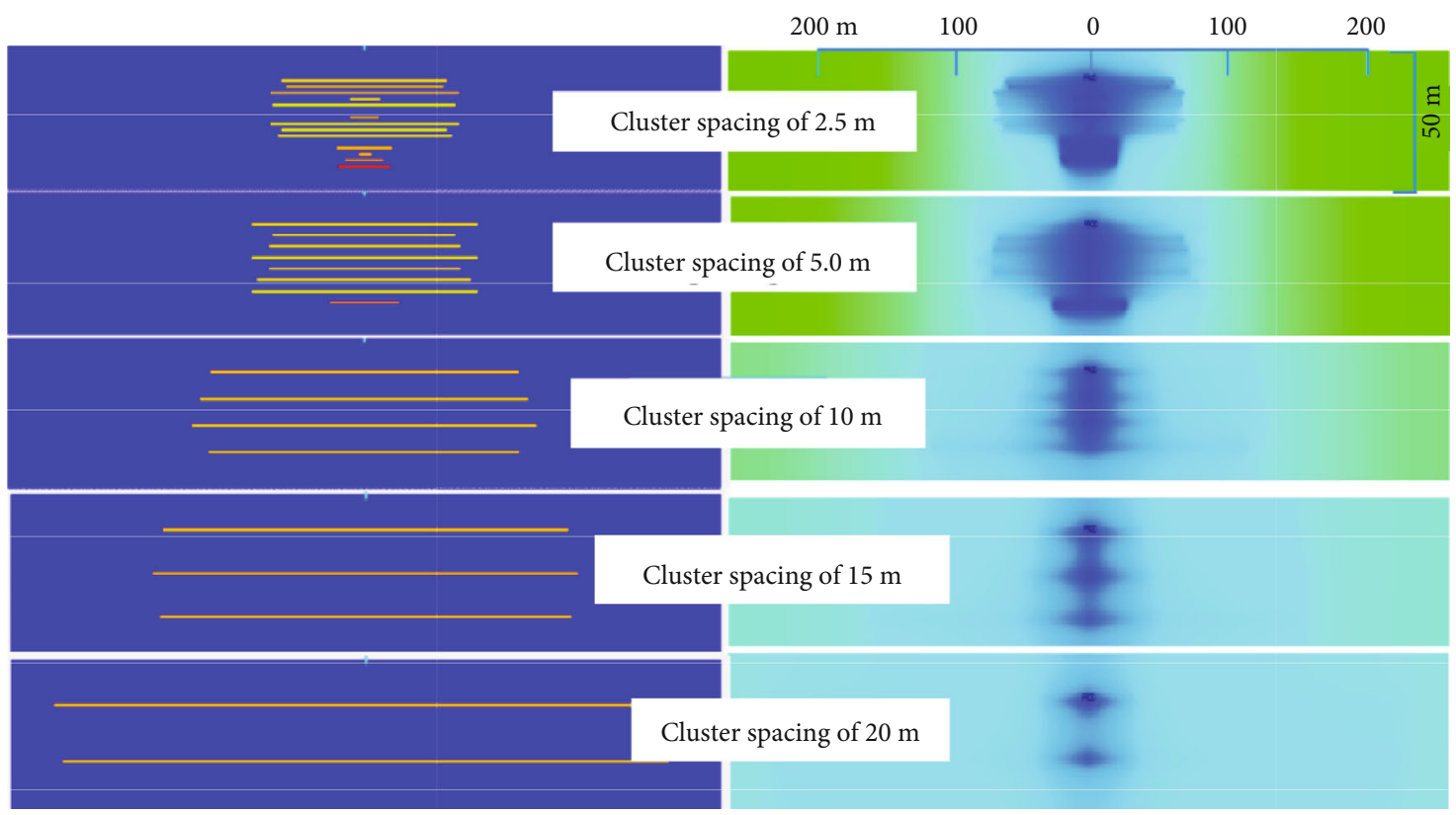

Figure 12: Pressure drawdown under different cluster spacings.

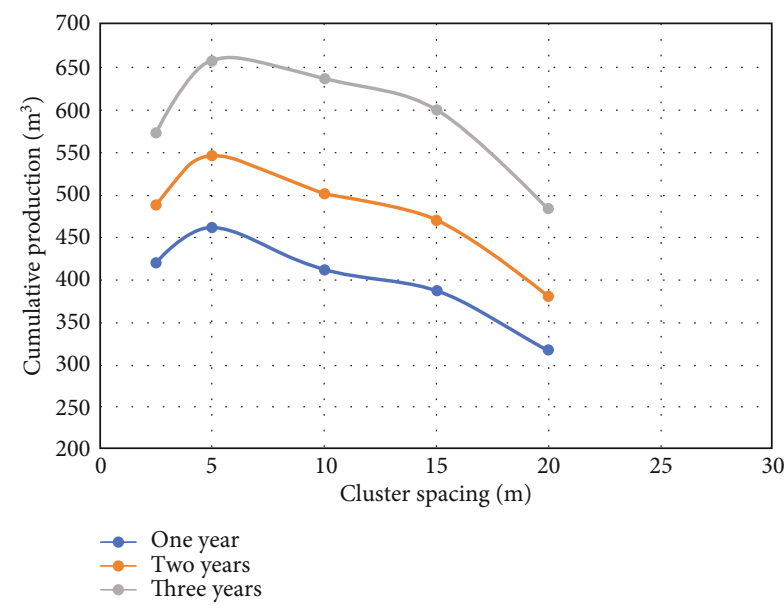

FIGURE 13: Cumulative production under different cluster spacings at $400 \mathrm{~m}$ well spacing.

The designing of a multi-cluster perforation scheme begins with dividing the horizontal section into stages, followed by the selection of the perforation methods. The perforation locations are first determined by the examination of geological sweet spots, adjustment according to the engineering sweet spots, and optimization of hole numbers.

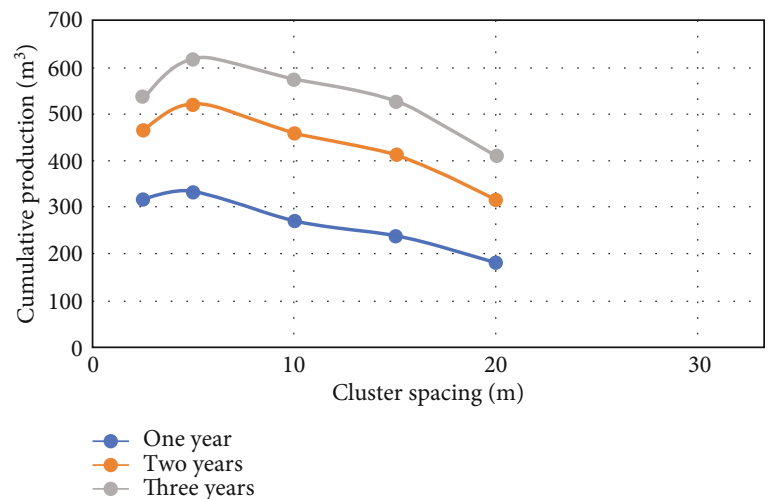

Figure 14: Cumulative production under different cluster spacings at $200 \mathrm{~m}$ well spacing.

A typical perforation optimization example of well $\mathrm{Y}$ is shown in Figure 17.

\section{Field Application and Result Evaluation}

The proposed optimization method is applied to 174 wells, which have an average lateral length of $1706 \mathrm{~m}$, divided into 22 stages with 94 clusters. The average fracture fluid volume 

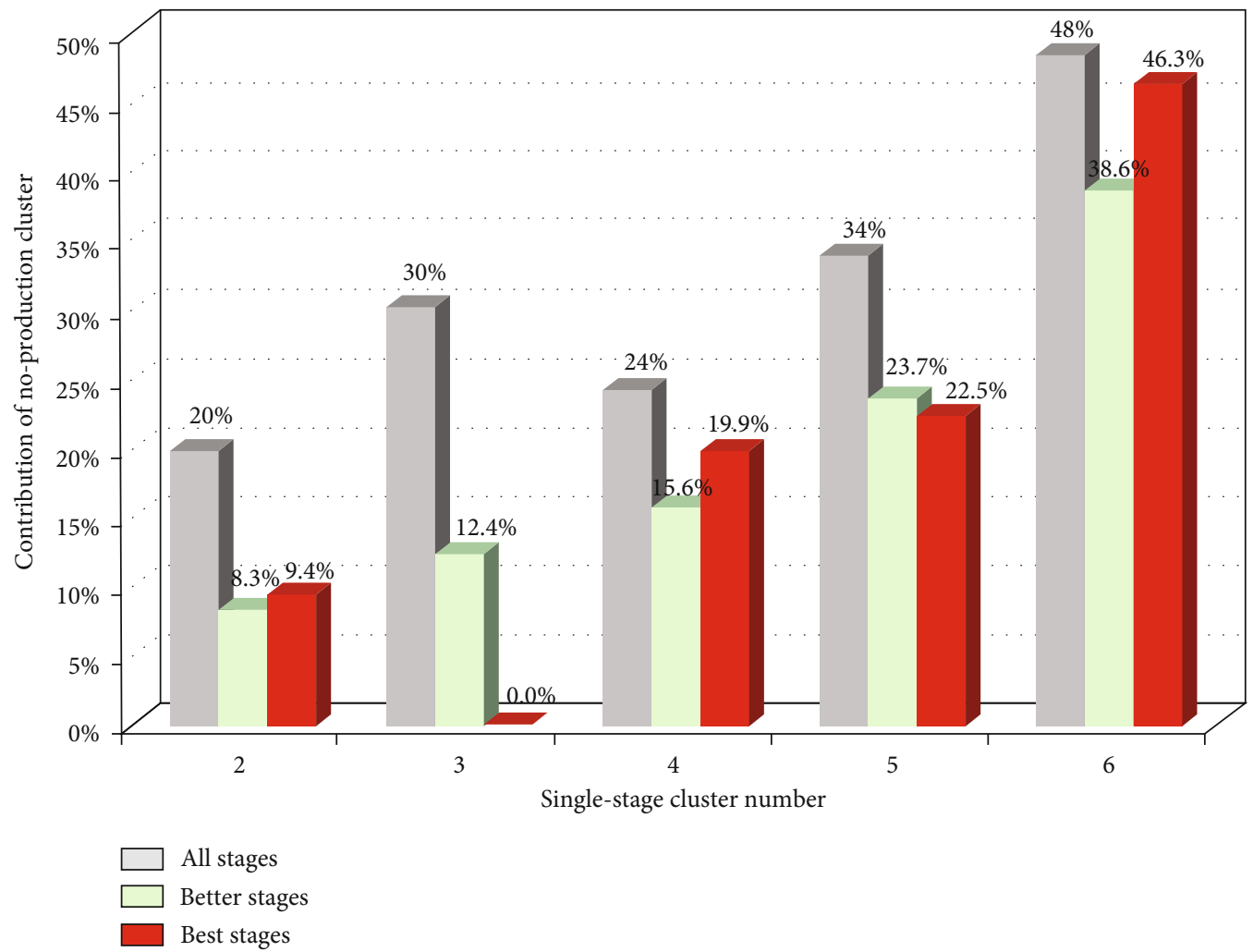

FIGURE 15: Comparison of single-stage cluster and effective clusters in Marcellus, Haynesville, Eagleford, Fayetteville, Barnett, and Woodford shales [27].

TABLE 4: Integrated sweet spot identification criteria.

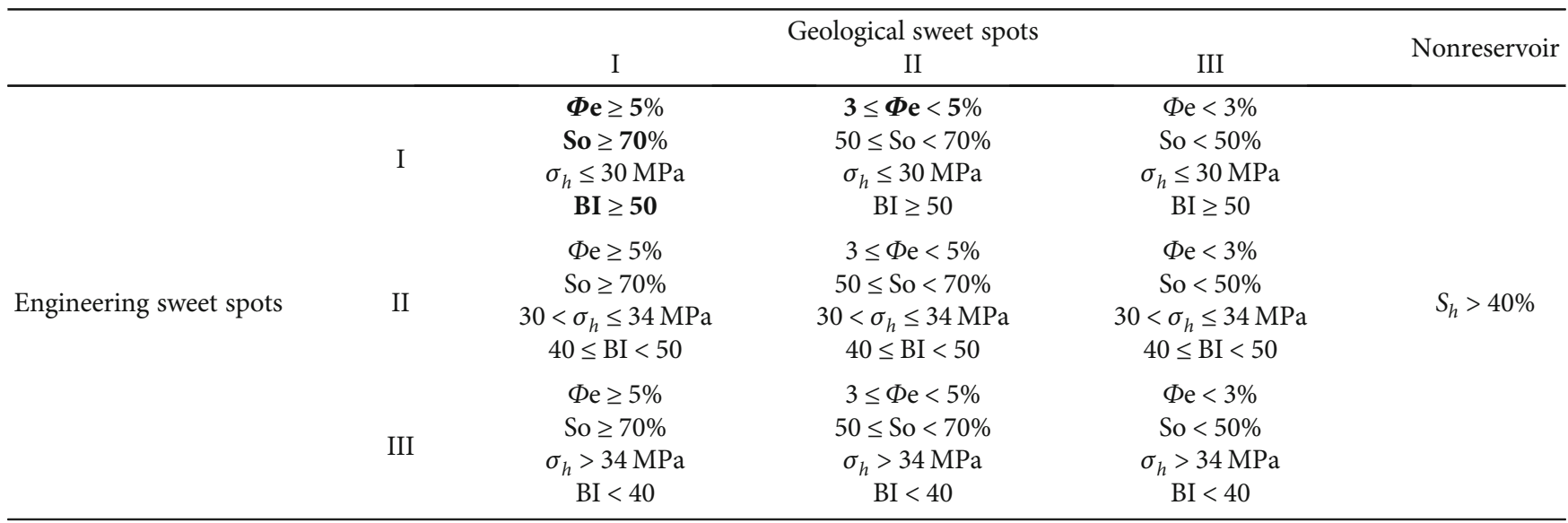

is $28294 \mathrm{~m}^{3}$, pumping at $10-15 \mathrm{~m}^{3} / \mathrm{min}$, with proppant usage at $3146 \mathrm{~m}^{3}$. The fracture spacing is $5-15 \mathrm{~m}$, with a fracture density of 7.8 fracture $/ 100 \mathrm{~m}$. The most fractured stages are 48 with 248 clusters, and the highest fluid and proppant volumes are $72000 \mathrm{~m}^{3}$ and 12000 ton, respectively. Mircoseismic monitoring indicated the minimized unstimulated reservoir volume and that the reservoir is largely stimulated at more than $90 \%$ SRV. The initial post-frac production increased from 10 ton/day to 16.8 ton/day. The first-year cumulative production reached 4680 ton, and the decline rate dropped from $42.5 \%$ to $27.8 \%$. The cumulative production in the third year is estimated at 8766 ton. Horizontal wells with a lateral length of $1500 \mathrm{~m}$ and well spacing of $400 \mathrm{~m}$ could produce a EUR of 24000 ton/well with an investment return rate of $9.11 \%$.

\section{Conclusion}

(1) Band-shaped fractures are created in Chang-7 shale oil reservoir stimulations. The primary fracture generated the secondary fractures, which further activated the natural fractures and induced shear failure. 


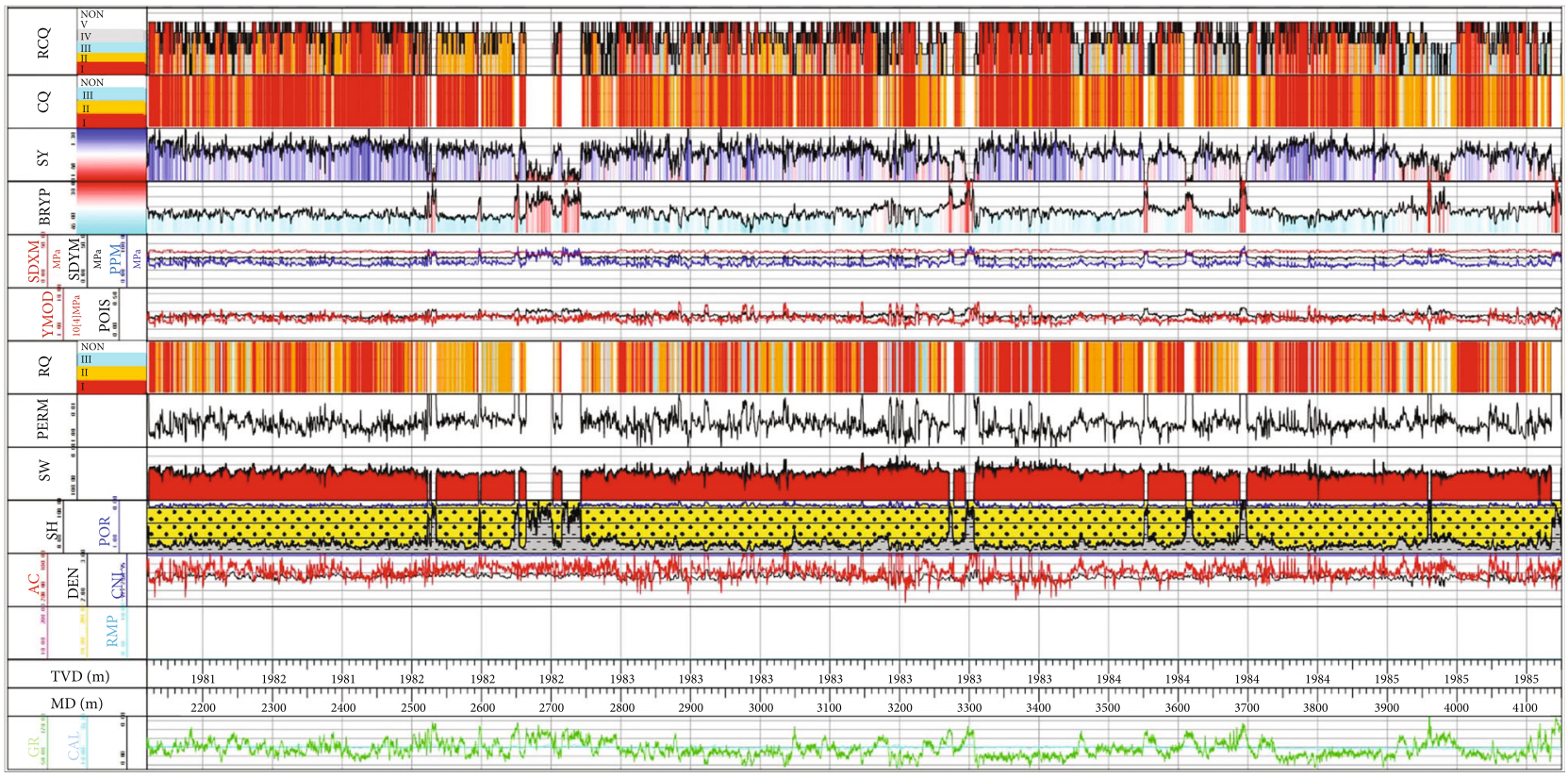

FIgURE 16: Integrated sweet spot identification in well Y.

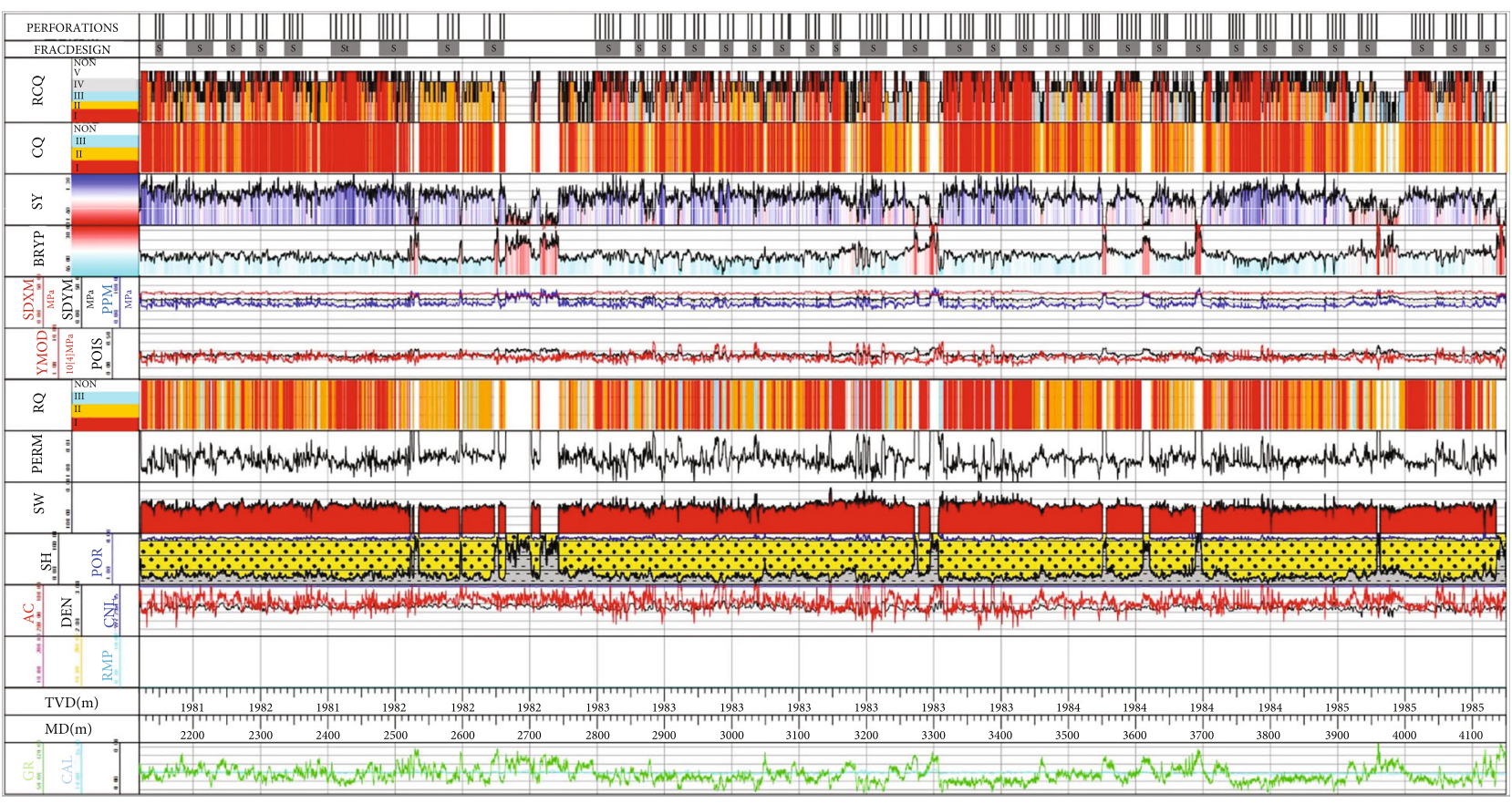

FIGURE 17: Perforation optimization example of well Y.

Macrofractures are perpendicular to the minimum principal stress. Secondary fractures and activated natural fractures are distributed around the primary fracture in the form of type I and II failures

(2) The current fracturing design scheme for the efficient development of Chang-7 reservoir has been formed according to the fracture parameter optimization and the design basis of shale oil reservoir treatment
(3) Based on the shale reservoir classification and evaluation, this study established a multicluster perforation optimization technology for horizontal wells in shale reservoirs with the goal of fully initiating multiple clusters and fully utilizing the fracture sweet spots

(4) The proposed optimization methods are applied to the field operations and great production enhancements are achieved 


\section{Data Availability}

Data are available on request.

\section{Conflicts of Interest}

The authors declare that there is no conflict of interest regarding the publication of this paper.

\section{Acknowledgments}

This study is sponsored by the "Demonstration Project of Tight Oil Development in the Ordos Basin" (2017ZX05069), "Demonstration Project of Low Permeability Reservoir Development in the Ordos Basin" (2016ZX05050), and "Tight Oil Accumulation, Exploration and Development" (2016ZX05046).

\section{References}

[1] L. Mu, Z. Zhao, X. Li et al., "Fracturing technology of stimulated reservoir volume with subdivision cutting for shale oil horizontal wells in Ordos Basin," Oil and Gas Geology, vol. 40, pp. 626-635, 2019.

[2] G. Sheng, H. Zhao, Y. Su et al., "An analytical model to couple gas storage and transport capacity in organic matter with noncircular pores," Fuel, vol. 268, p. 117288, 2020.

[3] G. Sheng, Y. Su, and W. Wang, "A new fractal approach for describing induced-fracture porosity/permeability/ compressibility in stimulated unconventional reservoirs," Journal of Petroleum Science and Engineering, vol. 179, pp. 855-866, 2019.

[4] J. Ciezobka, J. Courtier, and J. Wicker, "Hydraulic fracturing test site (HFTS) project overview and summary of results," SPE/AAPG/SEG Unconventional Resources Technology Conference, 2018, Houston, TX, United States, July 2018, 2018Unconventional Resources Technology Conference (URTEC).

[5] J. F. W. Gale, S. J. Elliott, and S. E. Laubach, "Hydraulic fractures in core from stimulated reservoirs: core fracture description of HFTs slant core, Midland Basin, West Texas," SPE/AAPG/SEG Unconventional Resources Technology Conference, 2018, Houston, TX, United States, July 2018, 2018Unconventional Resources Technology Conference (URTEC).

[6] A. P. Bunger, "A photometry method for measuring the opening of fluid-filled fractures," Measurement Science and Technology, vol. 17, no. 12, pp. 3237-3244, 2006.

[7] D. Zhou, G. Zhang, P. Zhao, Y. Wang, and S. Xu, "Effects of post-instability induced by supercritical CO2 phase change on fracture dynamic propagation," Journal of Petroleum Science and Engineering, vol. 162, pp. 358-366, 2018.

[8] D. Zhou, G. Zhang, Y. Wang, and Y. Xing, "Experimental investigation on fracture propagation modes in supercritical carbon dioxide fracturing using acoustic emission monitoring," International Journal of Rock Mechanics and Mining Sciences, vol. 110, pp. 111-119, 2018.

[9] Y. Chitrala, C. Moreno, C. Sondergeld, and C. Rai, "An experimental investigation into hydraulic fracture propagation under different applied stresses in tight sands using acoustic emissions," Journal of Petroleum Science and Engineering, vol. 108, pp. 151-161, 2013.
[10] G. Dresen, S. Stanchits, and E. Rybacki, "Borehole breakout evolution through acoustic emission location analysis," International Journal of Rock Mechanics and Mining Sciences, vol. 47, no. 3, pp. 426-435, 2010.

[11] J. Groenenboom and D. B. Van Dam, "Monitoring hydraulic fracture growth: laboratory experiments," Geophysics, vol. 65, no. 2, pp. 603-611, 2000.

[12] D. B. Van Dam, C. J. De Pater, and R. Romijn, "Analysis of hydraulic fracture closure in laboratory experiments," Proceedings of the 1998 SPR/ISRM Rock Mechanics In Petroleum Engineering, EUROCK. Part 1 (of 2), 1998, Trondheim, Norway, July 1998, 1998Soc Pet Eng (SPE).

[13] F. Renard, D. Bernard, J. Desrues, and A. Ougier-Simonin, “3D imaging of fracture propagation using synchrotron X-ray microtomography," Earth and Planetary Science Letters, vol. 286, no. 1-2, pp. 285-291, 2009.

[14] M. J. AlTammar and M. M. Sharma, "Effect of borehole pressurization scheme on breakdown pressure," Rock Mechanics and Rock Engineering, vol. 52, no. 8, pp. 2709-2715, 2019.

[15] P. A. Sookprasong, R. S. Hurt, C. C. Gill, and R. F. Lafollette, "Fiber optic DAS and DTS in multicluster, multistage horizontal well fracturing: Interpreting hydraulic fracture initiation and propagation through diagnostics," SPE Annual Technical Conference and Exhibition, 2014, Amsterdam, Netherlands, October 2014, 2014Society of Petroleum Engineers (SPE).

[16] X. Yang, G. Zhang, X. Du et al., "Measurement and implications of the dynamic fracture width in hydraulic fracturing using FBG strain sensors," 51st US Rock Mechanics / Geomechanics Symposium, 2017, San Francisco, CA, United States, June 2017, 2017American Rock Mechanics Association (ARMA).

[17] N. H. Cuevas, Electrokinetic coupling in hydraulic fracture propagation, ProQuest LLC, 2009.

[18] K. K. Chong, W. V. Grieser, A. Passman, C. H. Tamayo, N. Modeland, and B. Burke, "A completions guide book to shale-play development: a review of successful approaches towards shale-play stimulation in the last two decades," Society of Petroleum Engineers - Canadian Unconventional Resources and International Petroleum Conference 2010, 2010, Calgary, Alberta, Canada, October 2010, 2010.

[19] M. Mullen and M. Enderlin, "Fracability index - more than just calculating rock properties," SPE Annual Technical Conference and Exhibition 2012: Unconventional Wisdom, 2012, San Antonio, TX, United States, October 2012, 2012Society of Petroleum Engineers (SPE).

[20] C. Fang and M. Amro, "Influence factors of fracability in nonmarine shale," European Unconventional Resources Conference and Exhibition 2014: Unlocking European Potential, vol. 2, 2014, pp. 1196-1202, Vienna, Austria, February 2014, Society of Petroleum Engineers.

[21] Y. Hu, M. E. G. Perdomo, K. Wu et al., "A novel model of brittleness index for shale gas reservoirs: confining pressure effect," SPE Asia Pacific Unconventional Resources Conference and Exhibition, 2015, Brisbane, QLD, Australia, November 2015, 2015Society of Petroleum Engineers.

[22] X. Jin, S. N. Shah, J.-C. Roegiers, and B. Zhang, “An integrated petrophysics and geomechanics approach for fracability evaluation in shale reservoirs," SPE Journal, vol. 20, no. 3, pp. 518 526, 2015.

[23] J. Xu and S. Sonnenberg, "Brittleness and rock strength of the Bakken formation, Williston basin, North Dakota," SPE/AAPG/SEG Unconventional Resources Technology 
Conference 6, 2016, San Antonio, TX, United States, August 2016, 2016Unconventional Resources Technology Conference (URTEC).

[24] C. Cipolla, X. Weng, H. Onda, T. Nadaraja, U. Ganguly, and R. Malpani, "New algorithms and integrated workflow for tight gas and shale completions," SPE Annual Technical Conference and Exhibition, vol. 4, 2011, pp. 2950-2967, Denver, CO, United States, October-November 2011, Society of Petroleum Engineers (SPE).

[25] H. Liu, Y. Luo, X. Li et al., "Advanced completion and fracturing techniques in tight oil reservoirs in ordos basin: a workflow to maximize well potential," International Petroleum Technology Conference 2013: Challenging Technology and Economic Limits to Meet the Global Energy Demand, 2013, Beijing, China, March 2013, 2013.

[26] E. Wigger, A. Viswanathan, K. Fisher, R. Slocombe, P. Kaufman, and C. Chadwick, "Logging solutions for completion optimization in unconventional resource plays," European Unconventional Resources Conference and Exhibition: Unlocking European Potential, 2014, Vienna, Austria, February 2014, 2014Society of Petroleum Engineers.

[27] C. Miller, G. Waters, and E. Rylander, "Evaluation of production log data from horizontal wells drilled in organic shales," Society of Petroleum Engineers - SPE Americas Unconventional Gas Conference 2011, UGC 2011, Society of Petroleum Engineers (SPE), 2011, pp. 623-645, The Woodlands, Texas, USA, June 2011. 